OPEN ACCESS

Edited by:

Mark Mapstone,

University of California, Irvine,

United States

Reviewed by:

Robert Friedland,

University of Louisville, United States

Elena Marcello,

Università degli Studi di Milano, Italy

${ }^{*}$ Correspondence:

Eugenia Trushina

trushina.eugenia@mayo.edu

Specialty section:

This article was submitted to

Neurodegeneration,

a section of the journal

Frontiers in Neurology

Received: 20 October 2017

Accepted: 13 December 2017

Published: 12 January 2018

Citation:

Wilkins JM and Trushina E (2018) Application of Metabolomics in

Alzheimer's Disease.

Front. Neurol. 8:719.

doi: 10.3389/fneur.2017.00719

\section{Application of Metabolomics in Alzheimer's Disease}

\author{
Jordan Maximillian Wilkins ${ }^{1}$ and Eugenia Trushina ${ }^{1,2 *}$ \\ 'Mitochondrial Neurobiology and Therapeutics Laboratory, Department of Neurology, Mayo Clinic, Rochester, MN, \\ United States, ${ }^{2}$ Department of Molecular Pharmacology and Experimental Therapeutics, Mayo Clinic, Rochester, MN, \\ United States
}

Progress toward the development of efficacious therapies for Alzheimer's disease (AD) is halted by a lack of understanding early underlying pathological mechanisms. Systems biology encompasses several techniques including genomics, epigenomics, transcriptomics, proteomics, and metabolomics. Metabolomics is the newest omics platform that offers great potential for the diagnosis and prognosis of neurodegenerative diseases as an individual's metabolome reflects alterations in genetic, transcript, and protein profiles and influences from the environment. Advancements in the field of metabolomics have demonstrated the complexity of dynamic changes associated with $A D$ progression underscoring challenges with the development of efficacious therapeutic interventions. Defining systems-level alterations in AD could provide insights into disease mechanisms, reveal sex-specific changes, advance the development of biomarker panels, and aid in monitoring therapeutic efficacy, which should advance individualized medicine. Since metabolic pathways are largely conserved between species, metabolomics could improve the translation of preclinical research conducted in animal models of $A D$ into humans. A summary of recent developments in the application of metabolomics to advance the AD field is provided below.

Keywords: Alzheimer's disease, metabolomics, lipidomics, biomarkers, animal models of Alzheimer's disease

\section{INTRODUCTION}

Alzheimer's disease $(\mathrm{AD})$ is the leading cause of dementia resulting in memory loss, difficulty with thinking, and behavioral changes (1). Patients with early-onset familial AD (FAD) carry mutations in genes coding for amyloid precursor protein (APP; chromosome 21), presenilin-1 (PS1; chromosome 14), and presenilin-2 (PS2; chromosome 1) (2). Each of these mutations results in an increased production of amyloid- $\beta(A \beta)$ peptides (3-6). However, the majority of $A D$ cases are sporadic $(>95 \%$ prevalence) without a specific genetic link. Individuals carrying the $\varepsilon 4$ allele of apolipoprotein $\mathrm{E}$ (APOE), a lipid transport protein, have increased risk for developing AD at a younger age (7). Approximately $25 \%$ of AD patients in the United States carry one or more copy of the APOE $\varepsilon 4$ allele (8). The disease is progressive with age being the greatest risk factor (9). According to the Alzheimer's Association, nearly two-thirds of Americans with AD are females (10). Women who are positive for the APOE $\varepsilon 4$ allele are at greater risk of developing AD compared to men with the same variant (11). Additionally, female APOE $\varepsilon 4$ carriers develop more severe behavioral changes compared to men (12). However, the molecular mechanisms behind these differences remain to be elucidated. To date, strategies approved for $\mathrm{AD}$ treatment provide only symptomatic relief for some individuals. Disappointingly, recent clinical trials that focused on the prevention of $A \beta$ production have consistently failed (13). Lack of success may be related to the enrollment of participants into clinical trials at a point when it may be too late to reverse or stop disease progression. Furthermore, several $\mathrm{A} \beta$-independent mechanisms including impaired calcium and lipid homeostasis, mitochondrial 
dysfunction, altered cell signaling, synaptic transmission, oxidative stress, and inflammation have been shown to contribute to $\mathrm{AD}$ pathogenesis (13). Therefore, targeting $\mathrm{A} \beta$ alone may not be sufficient to achieve therapeutic efficacy, especially during late stages of the disease (14). Indeed, it became increasingly recognized that cellular decline in $\mathrm{AD}$ patients begins up to 20 years prior to the manifestation of clinical symptoms. As AD progresses, multiple pathways are synergistically affected activating a vicious cycle that ultimately devastates neuronal formation of synapses resulting in declined cognitive function (15). Interestingly, metabolic decline is one of the earliest symptoms detected using fluorodeoxyglucose positron emission tomography (FDG-PET) in patients with mild cognitive impairment (MCI), an early stage of $\mathrm{AD}$ (16). This suggests that metabolism could play an essential role in early $\mathrm{AD}$ mechanisms. Depending on the stage of $\mathrm{AD}$ and individual traits (e.g., age, sex, race, etc.), treatment options may vary and most likely will require combinatorial therapy $(17,18)$. Thus, novel technologies for the unbiased detection of changes associated with early disease mechanisms could be instrumental in the development of biomarkers for preclinical and clinical diagnosis, prognosis, and monitoring the outcome of treatment.

Metabolomics is the newest systems biology approach where multiple platforms are utilized to measure levels of small molecule metabolites in biological samples (19). Metabolic signatures are unique to an individual wherein perturbations in metabolite levels may inform on the disease state and underlying mechanisms of the disorder. The strength of metabolomics is in its ability to identify dynamic, qualitative, and quantitative changes in a large number of metabolites (in the thousands) representing alterations in multiple functional networks. Indeed, Oliver et al. first used the term metabolome to emphasize the importance of measuring changes in metabolite concentrations as a result of altered gene expression (20). Initially utilized as a high-throughput analytical tool primarily in studies related to toxicology, metabolomics has become increasingly used to research metabolic perturbations in multiple human diseases including $\mathrm{AD}$. The availability of biorepositories, such as Coriell Cell Repository and Alzheimer's Disease Neuroimaging Initiative (ADNI), which contain biofluids and tissue samples from control $(\mathrm{CN})$ and $\mathrm{AD}$ patients provide an outstanding opportunity to advance the understanding of sex- and diseasespecific metabolic signatures and mechanisms. As blood is a readily available biofluid for recurrent measures, longitudinal studies using metabolomics could significantly enhance the precision of individualized medicine. Moreover, since metabolic pathways are largely conserved between species, application of metabolomics could provide a strong tool to translate experimental findings in preclinical mouse models to humans. Below we review recent applications of metabolomics to develop disease biomarkers, conduct preclinical drug discovery, and advance our knowledge of the etiology and pathogenesis of AD.

\section{METABOLIC DECLINE IN AD}

In patients with $\mathrm{MCI}$, a prodromal stage of $\operatorname{AD}(21,22)$, early abnormalities are associated with reduced glucose utilization detected using FDG-PET $(23,24)$. This brain hypometabolism occurs $\sim 20$ years prior to the manifestation of clinical symptoms suggesting that metabolic dysfunction is a contributing factor for AD development (6-9). The brain is highly dependent on glucose consuming approximately $20 \%$ of total glucose-derived energy while accounting for about $2 \%$ of body weight (25). When glycolytic functions in the brain are perturbed, compensatory mechanisms switch to alternative fuel sources to maintain energy homeostasis (Figure 1) (26). Indeed, white matter degeneration in the brain tissue of aged wild-type mice is linked to the catabolism of lipids in order to compensate for reduced glucose utilization, which could be similar to that observed in the aging female brain (27). Supplementation with ketone bodies in AD transgenic mice and patients suggest that a ketogenic diet may improve cognition (27-29). Studies, including our own, have shown unique metabolic signatures associated with altered energy homeostasis in plasma and cerebrospinal fluid (CSF) of patients with MCI, which became more pronounced in patients with AD (30-32). Metabolic networks perturbed early in MCI individuals included lysine metabolism, tricarboxylic acid (TCA) cycle, lipid metabolism, and mitochondrial ketone bodies when compared to healthy individuals (30). In AD patients, metabolic alterations in multiple networks including neurotransmission and inflammation were detected in both CSF and plasma; however, the most pronounced changes in energetic pathways remained (30). Similar findings were also observed in multiple mouse models of $A D$ where changes in metabolic pathways related to energetic stress in female mice were greater compared to males (33). By identifying longitudinal changes in the metabolic networks of $\mathrm{CN}, \mathrm{MCI}$, and $\mathrm{AD}$ patients, it is possible to establish panels of metabolic biomarkers and gain valuable mechanistic insight into disease mechanisms. With the recent failure of clinical trials aimed to modulate $A \beta$ production, the attention in preclinical drug discovery and academic research has shifted toward the identification of new therapeutic targets and early mechanisms of AD including altered brain energetics and mitochondrial dysfunction (34). As metabolomics allows monitoring changes in multiple connected networks essential for understanding complex metabolic alterations, its application in $\mathrm{AD}$ research is gaining momentum.

\section{ANALYTICAL PLATFORMS}

Metabolomics encompasses several techniques including untargeted metabolomics, targeted metabolomics, lipidomics, and fluxomics (35-37). Untargeted metabolomics measures hundreds of metabolites in order to identify metabolic signatures related to a particular disease state or phenotype. This approach provides relative changes in metabolites and is useful for discovery projects where affected metabolic pathways are unknown. Targeted metabolomics provides quantitative measurements of a defined set of metabolites in a pathway of interest (e.g., glycolysis or TCA cycle). Lipidomics estimates changes in lipid profiles and requires specialized protocols for the detection and analysis of water-insoluble metabolites. Fluxomics incorporates stable isotope tracers to provide a dynamic, as opposed to static, assessment of metabolic changes and is done in cells or in vivo. Most often, heavy carbon $\left({ }^{13} \mathrm{C}\right)$ precursors are introduced into a system, which can be traced through a metabolic pathway by measuring 


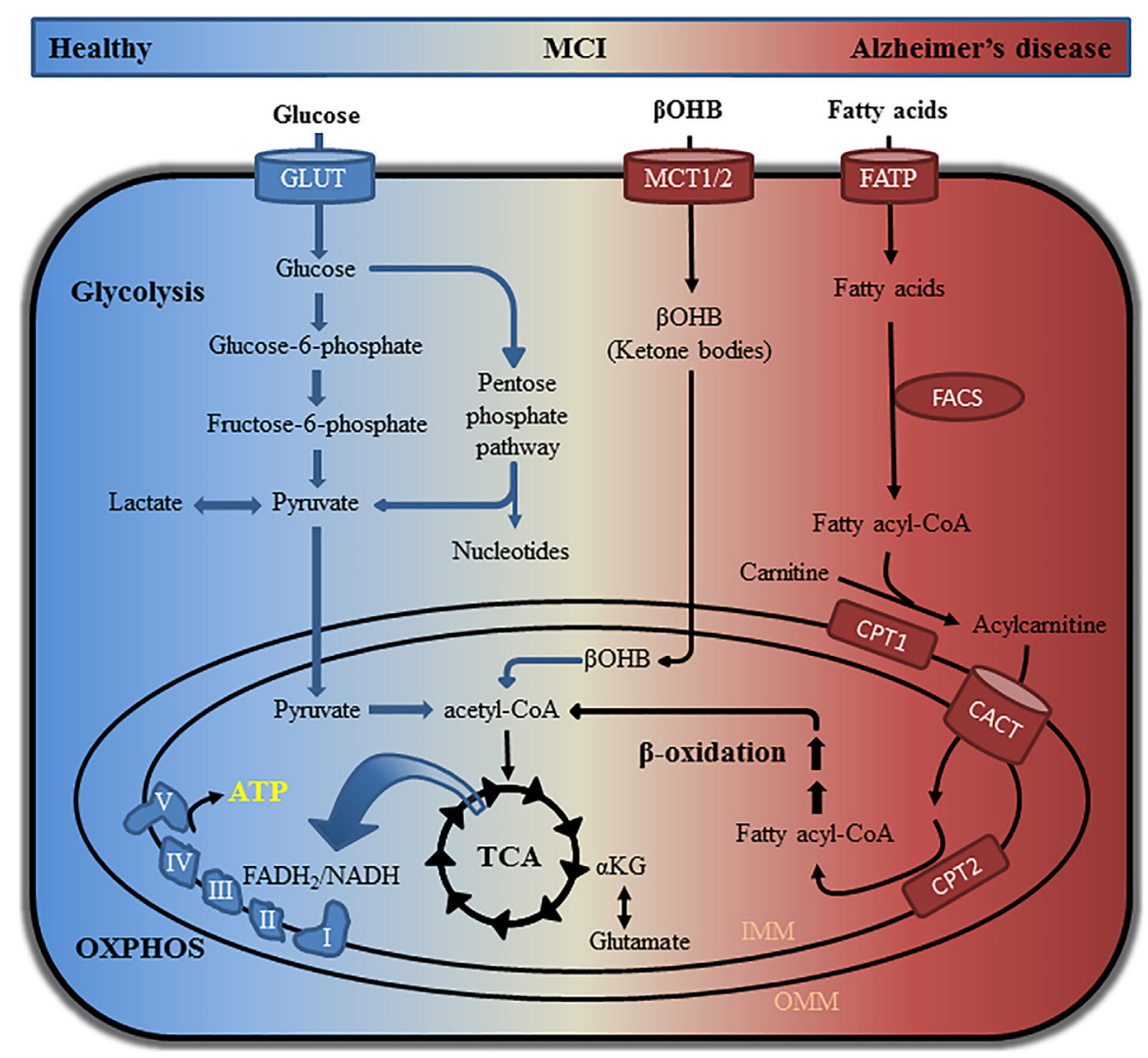

FIGURE 1 | Pathways involved in glucose, ketone body, and lipid metabolism. Glucose can be catabolized via glycolysis or the pentose phosphate pathway to produce intermediate metabolites that promote cell growth and function. Oxidation of glucose generates pyruvate, which is shuttled into mitochondria where it is converted to acetyl-CoA. Utilization of acetyl-CoA in the TCA cycle generates several intermediates that can be used for nucleotide, lipid, and amino acid synthesis. Electrons from the reducing equivalents $\mathrm{NADH}$ and $\mathrm{FADH}_{2}$ are used for oxidative phosphorylation (OXPHOS) to generate ATP. Healthy neurons are highly glycolytic catabolizing glucose via glycolysis and the TCA cycle in order to produce ATP through OXPHOS. Metabolic instability and decreased glucose utilization in AD patients can be detected by metabolomics approaches and fluorodeoxyglucose positron emission tomography. Impaired glycolytic processes in the brain can cause a shift toward the use of alternative fuel sources including ketone bodies and fatty acids. Processing of ketone bodies and fatty acids can produce acetyl-CoA for use in the TCA cycle and OXPHOS. $\alpha$ KG, alpha-ketoglutaric acid; $\beta O H B, \beta$-hydroxybutyric acid; CACT, carnitine acylcarnitine translocase; CPT1/CPT2, carnitine palmitoyltransferase 1/2; FACS, fatty acyl-CoA synthetase; FADH2, flavin adenine dinucleotide + hydrogen (H); FATP, fatty acid transport protein; GLUT, glucose transporter; IMM, inner mitochondrial membrane; MCT1/MCT2, monocarboxylate transporter 1/2; NADH, nicotinamide adenine dinucleotide (NAD) + hydrogen (H); OMM, outer mitochondrial membrane; TCA, tricarboxylic acid.

different mass isotopomers providing insight into the flux (rate) through a specific network. Each of these applications can be done in a variety of samples including cells, tissue, and biofluids.

Metabolites are small molecules $(<1,500 \mathrm{Da})$ implicated in most biological functions (38). The human metabolome is estimated to contain approximately 150,000 or more metabolites (39). Currently, the Human Metabolome Database contains over 100,000 metabolite entries (40). While a large fraction of human metabolites are unidentified, significant efforts are dedicated toward their discovery and identification. Due to the complex nature of the human metabolome and the diversity of sample composition, several analytical platforms have been adopted for proper detection of each group of metabolites. Mass spectrometry (MS) and nuclear magnetic resonance (NMR) spectroscopy are two analytical platforms regularly used for detection, quantification, and characterization of metabolites. A comparison of NMR and MS is outlined in Table $\mathbf{1 .}$
Nuclear magnetic resonance spectroscopy is a quantitative non-destructive technique that provides detailed information on molecular structure. Several advantages of NMR include minimal sample preparation, high-throughput capability, low cost per sample, and excellent data acquisition and reproducibility (41). However, NMR has relatively low sensitivity and limited detection of low molecular weight molecules (42). The use of high-field magnets, cryogenically cooled probes, and microcoil detectors can increase sensitivity $(43,44)$ but usually leads to longer times of analysis.

Mass spectrometry-based metabolomics offers higher sensitivity (femtomole levels) and the capability of detecting a broader range of metabolites. Biological samples are typically separated prior to MS analysis using various chromatography techniques including gas chromatography (GC) (45), liquid chromatography (LC) $(46,47)$, ultraperformance LC (UPLC) (48), high pressure LC (47), capillary electrophoresis/electrospray ionization (49), 
TABLE 1 | Analytical platforms utilized for metabolomics research.

\begin{tabular}{|c|c|c|}
\hline & Nuclear magnetic resonance & Mass spectrometry \\
\hline Platform cost & - High & - Moderate \\
\hline Analysis & $\begin{array}{l}\text { - Untargeted analysis } \\
\text { - Reproducibility is high }\end{array}$ & $\begin{array}{l}\text { - Targeted analysis } \\
\text { - Untargeted analysis } \\
\text { - Reproducibility is moderate }\end{array}$ \\
\hline Sample preparation & $\begin{array}{l}\text { - Minimal preparation } \\
\text { - Can be directly applied to biofluids and intact tissues } \\
\text { - Sample recovery is possible }\end{array}$ & $\begin{array}{l}\text { - Moderate preparation } \\
\text { - Metabolite extraction is usually required } \\
\text { - GC-MS is volatile and typically requires derivatization } \\
\text { - LC-MS can form adducts }\end{array}$ \\
\hline Sensitivity & $\begin{array}{l}\text { - Low detection range (micromolar) } \\
\text { - Requires protonated compounds } \\
\text { - Detects most organic molecules }\end{array}$ & $\begin{array}{l}\text { - High detection range (femtomolar) } \\
\text { - Detects most organic molecules } \\
\text { - Detects some inorganic molecules }\end{array}$ \\
\hline Measurements & $\begin{array}{l}\text { - Detects all metabolites in a single measurement within detectable range } \\
\text { - Spectral analysis is demanding }\end{array}$ & $\begin{array}{l}\text { - Requires multiple techniques for a comprehensive analysis } \\
\text { - Has broader range of metabolite detection }\end{array}$ \\
\hline
\end{tabular}

Fourier transform (FT) infrared spectroscopy (50), and FT ion cyclotron resonance (51). Chromatography coupled to MS offers a multidimensional analysis providing data related to chemical structure, mass, isotope distribution, and detection of unidentified molecules (52). For these reasons, LC- and GC-MS are often the preferred platforms. However, LC- and GC-MS require elaborate sample preparation, which can reduce metabolite recovery (53). Additionally, separation of molecules increases the time of analysis involving multiple runs for a large batch of samples leading to inter-batch variation, which is a common issue for MS-based metabolomics. Furthermore, while the selectivity of LC- and GC-MS (non-volatile and volatile, respectively) improves sensitivity, parallel application of the techniques is often required for a comprehensive analysis of the metabolome.

\section{APPLICATION OF METABOLOMICS IN HUMAN SAMPLES}

One of the most promising applications of metabolomics is the development of biomarker panels to detect alterations in multiple interconnected networks. Metabolomics-based biomarkers could provide comprehensive information compared to a single metabolite approach (54). To date, the definitive diagnosis of AD can only be done by postmortem examination of brain tissue for the presence of $A \beta$ plaques and neurofibrillary tangles (NFTs) composed of hyperphosphorylated microtubule-associated protein tau (MAPT; p-tau) (55). Provisional diagnosis of AD relies on the results of neuropsychological tests and appearance of typical symptoms of the disease (56). The use of biomarkers such as levels of $\mathrm{A} \beta$, p-tau, and t-tau (total-tau) in the CSF together with brain imaging using positron emission tomography with Pittsburgh compound B (PiB-PET) or magnetic resonance imaging increases the accuracy of diagnosis and helps to discriminate between different types of dementia. However, these tests are expensive. Furthermore, collection of CSF is associated with some health risk and may not be suitable for recurring testing. Therefore, the development of a simple, safe, and accurate test in readily available biological fluids, such as blood, is of great importance. In our earlier review, we described metabolomics studies performed prior to 2013 (57). Here, we summarize the most recent work (Table 2).

\section{METABOLIC CHANGES IN HUMAN POSTMORTEM BRAIN TISSUE AND CSF}

Using unbiased lipidomics and metabolomics approaches, Paglia and colleagues analyzed changes in postmortem frontal cortex from patients with AD and age- and sex-matched CN (58). Thirty four significantly altered metabolites that distinguished $\mathrm{AD}$ from $\mathrm{CN}$ belonged to six metabolic pathways: (1) alanine, aspartate, and glutamate metabolism, (2) arginine and proline metabolism, (3) cysteine and methionine metabolism, (4) glycine, serine, and threonine metabolism, (5) purine metabolism, and (6) pantothenate and CoA biosynthesis (58). Using partial least-squares regression, the authors correlated their metabolic findings with clinical significance (e.g., dementia and AD pathology). Results indicated that alanine, aspartate, and glutamate metabolism most strongly correlated with AD status while sex, age, body mass index, and postmortem interval had little to no correlation (58). Notably, their findings suggest that mitochondrial dysfunction, particularly aspartate metabolism, correlates with dementia and AD pathology. $N$-acetylaspartate (NAA) is a highly concentrated molecule in the brain, which is synthesized by mitochondria from aspartic acid and acetyl-CoA (71). Findings in AD patients showed a $15-20 \%$ reduction of NAA levels, which may relate to neuronal and mitochondrial dysfunction associated with decreased memory (71).

To identify brain region-specific metabolic changes, Snowden et al. used untargeted metabolomics to profile three brain regions differentially affected in AD patients (59). Brain tissue was collected from the cerebellum (CB), which is typically devoid of AD pathology, the middle frontal gyrus (MFG), and inferior temporal gyrus (ITG), which are vulnerable to $A \beta$ and tau deposition, respectively. Furthermore, this study included individuals with $\mathrm{AD}$, healthy $\mathrm{CN}$, and asymptomatic patients (ASYMAD) without evident cognitive impairment but a significant display of AD pathology at death (59). Tissue samples from ASYMAD patients with $\mathrm{AD}$ pathology lacking dementia provide a unique 
TABLE 2 | Application of metabolomics in samples from $\mathrm{MCl}$ and $\mathrm{AD}$ patients.

\begin{tabular}{ll}
\hline Analytical platform & Samples \\
\hline UPLC-HILIC-MS and ionKey/MS & Frontal cortex from 21 AD and $19 \mathrm{CN}$ \\
& \\
\hline HILIC LC-MS and GC-MS & $\begin{array}{l}\text { Cerebellum (little AD pathology), middle } \\
\text { frontal gyrus (increased AD pathology), } \\
\text { inferior temporal gyrus (increased tau } \\
\text { pathology) from 14 AD, 14 CN, and 15 } \\
\text { asymptomatic (display AD pathology } \\
\text { without dementia) }\end{array}$ \\
\hline
\end{tabular}

\begin{tabular}{ll}
\hline Biocrates Absolute IDQ p180 Kit & CSF from $50 \mathrm{AD}$-like ( $\downarrow$ A $\beta 42, \uparrow$ t-tau and \\
measured using FIA-MS/MS and & p-tau) and $50 \mathrm{CN}$
\end{tabular}
FIA-MS/MS and HPLC-MS/MS

\begin{tabular}{ll}
\hline UPLC-MS/MS & CSF from 6 AD and 6 CN \\
\hline $\begin{array}{ll}\text { Biocrates Absolute IDQ p180 Kit } & 732 \text { fasting plasma samples from ADNI } \\
\text { measured by UPLC-MS/MS } & \text { cohort }\end{array}$
\end{tabular}

732 fasting plasma samples from ADNI cohort
Findings

Reference

- Glycerophospholipid predominately altered in AD cortex

- $\uparrow$ NAA in AD cortex

- Mitochondrial dysfunction and aspartate metabolism correlated with dementia and AD pathology

- Global brain UFA perturbations as well as region-specific alterations in AD patients

- Within middle frontal gyrus $\downarrow$ Linoleic acid, linolenic acid, and arachidonic acid (CN > ASYMAD > AD) and $\uparrow$ docosahexanoic acid (AD > ASYMAD > CN) may serve as regional threshold markers associated with $A \beta$ plaques, tau tangles, and cognitive decline

- Two SM, five glycerophospholipids, and one AC were (60) significantly altered in CSF with pathological $A \beta$ and tau levels

- $\uparrow$ SM (d18:1/18:0) was 76\% specific and 66\% sensitive as a biomarker

- $\uparrow$ Gly, SAH, and $\downarrow$ SAM in AD CSF

- Established method for quantifying 17 metabolites of homocysteine-methionine metabolism

- Bonferroni analysis correlated 13 metabolites with AD pathogenesis

- CSF A342 metabolites: PC ae C36:2, PC ae 40:3, PC ae C42:4, PC ae C44:4, SM (OH) C14:1, SM C16:0

- CSF t-tau/Aß42 metabolites: C18, PC ae C36:2, SM C16:0, SM C20:2

- Cognitive decline metabolites: C14:1, C16:1, SM C20:2, $\alpha$-AAA, and Val

- Brain atrophy metabolites: C12, C16:1, PC ae C42:4, PC ae C44:4, $\alpha$-AAA, and Val

\begin{tabular}{ll}
\hline HRMS & Plasma from $37 \mathrm{CN}, 16 \mathrm{MCl}$, and 19 \\
& individuals who converted from $\mathrm{MCl}$ to $\mathrm{AD}$ \\
& (MCl_AD)
\end{tabular}

- Polyamine and saturated fatty acid biosynthesis was most altered with $\mathrm{MCl}$ vs $\mathrm{CN}$

- $\mathrm{MCl}$ AD vs CN showed differences in cholesterol and sphingolipid transport and saturated fatty acid biosynthesis

- MCl_AD vs MCl was most perturbed in cholesterol and sphingolipid transport and polyamine metabolism

- Polyamine metabolism and L-Arg metabolism were common between $\mathrm{CN}, \mathrm{MCl}$, and $\mathrm{MCl} \_\mathrm{AD}$
HPLC Lipidomics
Plasma from $\mathrm{CN}, \mathrm{MCl}$, and $\mathrm{AD}$ along with brain atrophy
- 10 molecules significantly altered that predicted AD patients with $79 \%$ accuracy including six ChEs following the trend $\mathrm{CN}>\mathrm{MCl}>\mathrm{AD}$

- PC36:5 decreased in AD plasma associated with hippocampal atrophy

- Ceramides were associated with hippocampal atrophy in younger (age < 75 years) group while PCs correlated at age $>75$ years

Biocrates Absolute IDQ p180 Kit Plasma from $73 \mathrm{CN}$ and 28 by UPLC-MS phenoconverters
- Identified 24 plasma metabolites for the detection of preclinical AD with 95\% accuracy

- $13 \downarrow$ PCs (PC ae C34:0, PC ae C36:4, PC ae C40:6, PC ae C42:1, PC aa C32:0, PC aa C34:4, PC aa C36:6, PC aa C38:0, PC aa C38:3, PC aa C38:6, PC aa C40:1, PC aa C40:5, lysoPC a C18:2)

- $6 \downarrow$ ACs (C3, C5, C5-OH (C3-DC-M), C9 C10:2, C18:1-OH) and $3 \uparrow A C s(C 10: 1, C 12: 1, C 16: 2)$

- Asn

- ADMA

- Developed a 12-metabolite panel for detection of superior memory

- valerylcarnitine, hydroxyhexadecadienylcarnitine, 3-hydroxypalmitoleylcarnitine, lysoPC a C28:1, lysoPC a C17:0, PC aa C38:5, Asp, Asn, Arg, histamine, citrulline, and nitrotyrosine
Biocrates Absolute IDQ p180 Kit measured by FIA-MS/MS and UPLC-MS
Plasma from 41 participants with superior memory, $109 \mathrm{CN}$, and $74 \mathrm{aMCl} / \mathrm{AD}$ 
TABLE 2 | Continued

\begin{tabular}{|c|c|c|c|}
\hline Analytical platform & Samples & Findings & Reference \\
\hline $1 \mathrm{HNMR}$ & Saliva from $9 \mathrm{AD}, 8 \mathrm{MCl}$, and $12 \mathrm{CN}$ & $\begin{array}{l}\text { - Group separation achieved using logistic regression models } \\
\text { - Strongest predictive markers between } \mathrm{MCl} \text { and } \mathrm{CN} \text { were } \\
\text { galactose, imidazole, and acetone with sensitivity and } \\
\text { specificity of } 90 \text { and } 94 \% \text {, respectively }\end{array}$ & (69) \\
\hline Faster UPLC-MS & Saliva from 256 AD and $218 \mathrm{CN}$ & $\begin{array}{l}\text { - PCA identified sphinganine-1-phosphate, ornithine, } \\
\text { phenyllactic acid, inosine, 3-dehydrocarnitine, and } \\
\text { hypoxanthine as significantly altered in AD saliva } \\
\text { - } \uparrow \text { sphinganine-1-phosphate in AD patients was a major } \\
\text { biomarker with sensitivity of } 99.4 \% \text { and specificity of } 98.2 \%\end{array}$ & $(70)$ \\
\hline
\end{tabular}

1 H NMR, proton nuclear magnetic resonance; $A C$, acylcarnitines where $C$ denotes species; $A D$, Alzheimer's disease; ADMA, asymmetric dimethylarginine; $A D N I$, Alzheimer's Disease Neuroimaging Initiative; aMCl, amnestic MCl; Arg, arginine; ASYMAD, asymptomatic patients; Asn, asparagine; Asp, aspartate; ChE, cholesteryl ester; CN, control; CSF, cerebrospinal fluid; FIA-MS/MS, flow injection analysis-MS/MS; GC-MS, gas chromatography-MS; Gly, glycine; HILIC, hydrophilic interaction liquid chromatography; HPLC-MS/MS, high-performance liquid chromatography-MS/MS; HRMS, high-resolution MS; lysoPC, lysophosphatidylcholine; MCl, mild cognitive impairment; MS, mass spectrometry; MS/MS, tandem mass spectrometry; NAA, N-acetylaspartate; PC a, phosphatidylcholine acyl; PC aa, phosphatidylcholine diacyl; PC ae, phosphatidylcholine acyl-alkyl; PCA, principle component analysis; p-tau, phospho-tau; SAH, S-adenosylhomocysteine; SAM, S-adenosylmethionine; SM, sphingomyelin; t-tau, total-tau; UFA, unsaturated fatty acid; UPLC-MS/MS, ultra performance liquid chromatography-MS/MS; Val, valine; $\alpha$-AAA, $\alpha$-aminoadipic acid.

longitudinal assessment. Additionally, observations made in brain regions differentially affected in $\mathrm{AD}$ enhance the understanding of spatial-temporal changes. The authors used untargeted metabolomics to measure 3,482 metabolites using LC-MS and an additional 1,415 metabolites using GC-MS. They identified six unsaturated fatty acids (UFAs; linoleic acid, linolenic acid, docosahexaenoic acid, eicosapentaenoic acid, oleic acid, and arachidonic acid) that correlated with $\mathrm{AD}$ pathology and clinical symptoms (59). The authors suggested that changes in the concentration of these UFAs may serve as regional threshold markers in the brain defining the onset of $A \beta$ - and tau-induced cognitive decline (59). In the ITG, levels UFAs had the greatest change in ASYMAD when compared to CN. The MFG had a consistent alteration in UFA abundance with $\mathrm{AD}>\mathrm{ASYMAD}>\mathrm{CN}$. Interestingly, the authors observed significant UFA changes in the $\mathrm{CB}$ of $\mathrm{AD}$ patients relative to $\mathrm{CN}$ suggesting that metabolic alterations are systemic affecting multiple brain regions irrelevant of the presence of $A \beta$ and/or tau pathology.

Cerebrospinal fluid is the extracellular fluid that surrounds the brain representing an ideal source for determining neurobiochemical changes that occur in the central nervous system of $\mathrm{AD}$ patients. Using a Biocrates Absolute IDQ p180 metabolomics kit, which targets five compound classes (acylcarnitines, amino acids, biogenic amines, hexoses, and phospho- and sphingolipids), Koal et al. analyzed 50 CSF samples from patients with AD-like pathology defined by decreased A $\beta 42$ and increased t-tau and p-tau CSF levels (60). Compared to healthy $\mathrm{CN}$, they identified eight metabolites that were significantly increased in the CSF samples with AD-like pathology including one acylcarnitine (C3), two sphingomyelins [SM (d18:1/18:0) and SM (d18:1/18:1)], and five glycerophospholipids (PC aa C32:0, PC aa C34:1, PC aa C36:1, PC aa C38:4, and PC aa C38:6) (60). Using logistic regression analysis with forward variable selection, SM (d18:1/18:0) was identified as a potential biomarker capable of distinguishing between AD-like and healthy $\mathrm{CN}$ (60). Sphingomyelins represent major components of myelin sheaths. Catabolism of myelin and sphingomyelin has been shown to provide an alternative fuel source (in the form of ketones) in multiple diseases including
$\mathrm{AD}$ and aging (27). Furthermore, sphingomyelin is enriched in lipid rafts that are also the site where gamma-secretases (PS1/ PS2) localize, which may influence the processing of APP (72). While samples used in the study by Koal et al. were not derived from patients clinically diagnosed with $\mathrm{AD}$, the concentration of SM (d18:1/18:0) significantly correlated with AD-like pathology as determined by levels of A $\beta$ and tau in the CSF (60) suggesting that this marker may serve for early detection of the disorder.

In another study, Guiraud et al. utilized UPLC-MS/MS to quantitate 17 metabolites of the methionine cycle in the CSF of patients diagnosed with AD (61). They applied a new multianalyte strategy to monitor both metabolites and cofactors of methionine metabolism simultaneously. Using this approach, Guiraud and colleagues identified significant increases of glycine and $S$-adenosylhomocysteine $(\mathrm{SAH})$ with decreased $S$-adenosylmethionine (SAM) in the CSF of patients diagnosed with AD (61). The metabolites SAM and SAH are key intermediates in the methionine cycle important for protein synthesis and maintaining cellular methylation of DNA, proteins, and neurotransmitters (73). In cells, methionine is primed forming SAM, which serves as a cofactor for methyl transferases. SAH is generated after transfer of the methyl group is complete. Dysregulation of methionine, SAM, and SAH metabolism has been linked to several neurodegenerative diseases including $\mathrm{AD}$ (74-76). For example, mice fed with an L-methionine-enriched diet had increased levels of $\mathrm{A} \beta$ oligomers and p-tau (77). Additionally, several studies have demonstrated a strong correlation between $\mathrm{AD}$ and altered DNA methylation profiles (78-80). Combined, these findings provide insight into possible epigenetic alterations that may explain the sporadic nature of AD.

\section{METABOLIC PROFILING IN HUMAN PLASMA}

Plasma is an easily accessible biofluid suitable for recurrent measures. Multiple studies were conducted in the plasma of patients with different severity of $\mathrm{AD}$ to establish metabolic 
changes indicative of the disease progression (57). Our earlier studies demonstrated that changes in metabolic pathways involved in altered energy homeostasis detected in the CSF of patients with $\mathrm{MCI}$ and $\mathrm{AD}$ could be accurately recapitulated in plasma (30). However, the reproducibility of results reported in a number of studies using metabolic profiling in plasma varied substantially (57). Part of the problem includes small sample sizes and inconsistent processing techniques. One of the largest metabolomics studies to date was conducted in plasma from $\mathrm{AD}$ patients collected within the ADNI cohort by researchers of the Alzheimer's Disease Metabolomics Consortium (18). In this study, Toledo et al. analyzed serum from over 700 ADNI participants and correlated metabolic changes with clinical data available for each patient including CSF levels of A $\beta 42$ and tau, brain structure assessed by MRI, and cognitive performance determined by ADAS-Cog scores (18, 81-83). Using Bonferroni multiple comparisons, Toledo et al. identified 13 key metabolites altered at the various stages of $\mathrm{AD}$. Six metabolites were associated with increased CSF A $\beta 42$ including PC ae C36:2, PC ae C40:3, PC ae C42:4, PC ae C44:4, SM (OH) C14:1, and SM $\mathrm{C} 16: 0$, and four were linked with t-tau/A $\beta 42$ ratio $(\mathrm{C} 18, \mathrm{PC}$ ae C36:2, SM C16:0, SM C20:2). Five metabolites (C14:1, C16:1, SM C20:2, $\alpha$-aminoadipic acid [ $\alpha$-AAA], and valine) accompanied decreased cognitive function while six (C12, C16:1, PC ae C42:4, $\mathrm{PC}$ ae $\mathrm{C} 44: 4, \alpha$-AAA, and valine) correlated with increased brain atrophy (18). For each of the clinical predictors of $\mathrm{AD}$, a decrease in valine and $\alpha$-AAA were detected while levels of acylcarnitines, PCs, and SMs increased. The integrated approaches taken by Toledo and colleagues provided valuable insight into mechanisms of $\mathrm{AD}$ (18). First, they found that changes in the membrane lipid PCs and SMs occurred in the initial stages of AD pathology associated with abnormal CSF A $\beta 42$ levels, which may suggest that membrane alterations involved in neurodegeneration begin early (18). Following aberrant $A \beta$ levels, the authors identified tau-associated changes in long-chain acylcarnitines and SMs implicated in lipid metabolism. Since tau-associated metabolite alterations preceded brain atrophy and cognitive decline and were distinctive from $\mathrm{A} \beta 42$ perturbations, these results may indicate intermediate changes that correlate with altered lipid metabolism and mitochondrial bioenergetics (18). This further suggests that tau-associated metabolic alterations could serve as an intermediate biomarker indicative of cognitive decline. Lastly, partial correlation networks and coexpression network analysis suggested that changes in brain volume and cognition (assessed by MRI and ADAS-Cog scores) correlated with a shift in substrate utilization from fatty acids to amino acids (18). This $\mathrm{AD}$-associated shift in energy metabolites provides new insights into metabolic transitions that occur late in the disease process. Amino acids, particularly alanine and glutamine in addition to threonine, glycine, and serine, can be used to synthesize glucose via gluconeogenesis (84). As the brain is highly glycolytic, this may indicate an attempt to reestablish glycolysis that is altered in AD (Figure 1). Taken together, this study suggests that specific metabolic changes occur during the progression of $\mathrm{AD}$ and that blood-based metabolite markers could improve disease diagnosis.

In line with results from Toledo et al. (18), several additional metabolomics studies have revealed perturbed metabolic profiles in the plasma of AD patients. Graham and colleagues (62) used high-resolution MS in a longitudinal study to analyze metabolic changes in plasma samples from 37 healthy $\mathrm{CN}, 16$ patients with MCI, and 19 patients that converted from MCI to AD (MCI_AD). Comparison of MCI to $\mathrm{CN}$ showed that polyamine metabolism and saturated fatty acid biosynthesis were highly altered. The most affected metabolic pathways when comparing MCI_AD to CN included cholesterol and sphingolipid transport and saturated fatty acid biosynthesis. Conversion from MCI to MCI_AD was associated with metabolic alterations in cholesterol and sphingolipid transport and polyamine metabolism. Consistently disrupted across all three comparisons, however, was polyamine metabolism and L-arginine metabolism suggesting that these metabolic pathways are highly implicated in the conversion of healthy individuals to MCI and AD (62). The authors further noted that several metabolites were shared across polyamine and L-arginine metabolism, which have been reported to be important for neuronal health, survival, growth, and cell death $(62,85-89)$. Polyamine synthesis begins in the mitochondria via conversion of arginine to ornithine by the enzyme arginase (ARG2) (90). Subsequent reactions lead to the production of polyamines (e.g., spermidine and spermine). Of note, methionine/SAM metabolism is required for polyamine synthesis, which was found to be significantly increased in the CSF of AD patients by Guiraud and colleagues $(61,90)$. The polyamines spermine and spermidine have also been shown to act as agonists for $N$-methyl-D-aspartate (NMDA) receptors that bind to the neurotransmitter glutamate (91). The drug memantine, approved for the treatment of $\mathrm{AD}$, is an NMDA antagonist, which reduces excitotoxicity of glutamate signaling protecting against synaptic loss and cognitive decline (92). Metabolic findings by Graham and colleagues suggest a role for polyamines in NMDA-mediated excitotoxicity in AD.

Proitsi el al. used untargeted lipidomics to compare plasma from 123 individuals $(40 \mathrm{CN}, 48 \mathrm{MCI}$, and $35 \mathrm{AD}$ patients from the Dementia Case Register cohort and EU funded AddNeuroMed study) (63). Using univariate analysis, Proitsi et al. identified 41 metabolites associated with AD. After applying Random Forest and backward elimination, the authors narrowed the list of metabolites to a panel of 10 molecules that could identify AD patients with $79 \%$ accuracy. Six of these metabolites were identified as cholesteryl esters (ChEs), which Proitsi et al. noted as a class of metabolites not previously associated with $\mathrm{AD}$ (63). However, previous findings have reported alterations of phosphatidylcholines (PCs) in $\mathrm{AD}(93,94)$, which are precursors for the synthesis of ChEs. The enzyme lecithin-cholesterol acyltransferase synthesizes ChEs from PC and cholesterol to allow for more efficient transport of cholesterol in the blood stream. In two recent follow-up studies from Legido-Quigley's group, the authors further implicated changes in plasma lipids in AD. Kim et al. demonstrated a correlation between altered lipid concentrations in $\mathrm{AD}$ patients and brain atrophy (64). Three ceramides (Cer16:0, Cer18:0, and Cer20:0) were elevated in the plasma of $\mathrm{AD}$ patients and were associated with hippocampal atrophy in adults younger than 75 years of age. For AD patients over 75 years of age, a decrease in PC38:6 and PC40:6 were linked to hippocampal atrophy. These findings suggest that impaired 
PC and ceramide metabolism could be associated with various stages of $\mathrm{AD}$ progression and hippocampal atrophy (64). Using additional samples from the Dementia Case Register cohort and EU funded AddNeuroMed study (148 AD and $152 \mathrm{CN}$ ), Proitsi et al. replicated their previous findings in the plasma of MCI and AD patients $(63,65)$. Proitsi further demonstrated a correlation between altered lipids (including new putative lipids) with $\mathrm{AD}$ progression and brain atrophy (65). Together, the results from Legido-Quigley's group support an association between altered plasma PCs, ChEs, and ceramides with $\mathrm{AD}$ progression, which is consistent with the implication of altered lipid metabolism in $\mathrm{AD}$ pathogenesis (27, 30, 95-97).

Mapstone and colleagues previously developed a panel of blood-based biomarkers that could predict the conversion of cognitively normal individuals to amnestic MCI (aMCI) or $\mathrm{AD}$, referred to as phenoconversion (66). Their panel consisted of 10 plasma lipids, which could predict phenoconversion of individuals (approximately 80 years of age) within a 2-3-year timeframe with $85 \%$ accuracy (66). However, low positive predictive values remained an issue reducing clinical value. More recently, using the same cohort, Fiandaca et al. refined and expanded the blood-based panel to include 24 metabolites resulting in increased positive predictive values (67). The updated panel consists of 13 glycerophosphatidylcholines (PCs), 9 acylcarnitines, asparagine, and asymmetric dimethylarginine (ADMA), which improved their predictive accuracy to $95 \%(67)$. These results are in line with other studies where plasma PCs, acylcarnitines, and amino acids were found to be altered in MCI and AD patients $(18,62-65)$. Additionally, two metabolomics studies using CSF or brain tissue from patients without cognitive impairment but with AD-like pathology also identified differentially regulated lipids and UFAs when compared to $\mathrm{CN}(59,60)$. In the CSF of AD patients, Guiraud et al. observed significant changes in SAM (61), which is needed for the generation of ADMA (98). These results strongly implicate lipids as pre- and post-symptomatic markers for dementia and AD. Furthermore, these data strengthen the notion that peripheral blood may be an appropriate biofluid that can reflect changes in the CSF and brain tissue.

Aging is characterized by a decline in memory and cognition and is considered the greatest risk factor for $\mathrm{AD}$. In search for metabolic markers of healthy aging, Mapstone et al. identified metabolites in older individuals (approximately 80-85 years of age) with superior memory performance compared to normal and $\mathrm{aMCI} / \mathrm{AD}$ patients (68). Participants were scored based on cognitive performance including attention, executive, language, memory, and visuospatial properties. Performance studies identified 41 participants with superior memory, 109 with normal memory performance, and 74 people were classified as having aMCI/AD. Plasma samples were analyzed using the Biocrates Absolute IDQ p180 Kit measured with FIA-MS/ MS and UPLC-MS. Comparison of individuals with superior memory to controls by least absolute shrinkage selection operator analysis revealed 12 metabolites capable of distinguishing between the two groups. The 12-metabolite panel included valerylcarnitine, hydroxyhexadecadienylcarnitine, 3-hydroxypalmitoleylcarnitine, lysoPC a C28:1, lysoPC a C17:0, PC aa
C38:5, aspartate, asparagine, arginine, histamine, citrulline, and nitrotyrosine (68). Using this panel, the authors were able to distinguish between the elderly with superior memory and $\mathrm{aMCI} / \mathrm{AD}$ or preclinical $\mathrm{AD}$ suggesting these markers may indicate early memory deficits (68). Interestingly, their previously identified 10-lipid panel (66), which putatively detected early signs of neurodegeneration, only modestly associated with the 12-metabolite healthy aging panel (68). Superior memoryassociated metabolites identified by Mapstone and colleagues may provide insight into metabolic pathways that are important for proper cognitive function.

\section{METABOLIC PROFILING IN HUMAN SALIVA}

Saliva is a readily accessible biofluid that contains proteins, mRNA, microRNA, enzymes for the breakdown of lipids and starches, and molecules important for biological functions including taste, lubrication, and immune responses (99-101). Unlike CSF and plasma, composition of saliva rapidly changes in response to biological stimuli $(102,103)$. In a recent study, Yilmaz et al. utilized NMR-based metabolomics to identify 22 salivary metabolites that were useful for distinguishing between $\mathrm{AD}$, MCI, and healthy patients (69). Group separation between AD and $\mathrm{CN}$ was achieved using logistic regression models identifying significant changes in the metabolites propionate and acetone (69). Similarly, galactose, imidazole, and acetone distinguished between MCI and $\mathrm{CN}$, while creatine and 5-aminopentanoate separated AD vs MCI (69). In another study using faster UPLC-MS, the authors analyzed the saliva from 256 patients with $\mathrm{AD}$ and 218 age-matched healthy controls (70). Using principal component analysis, Liang and colleagues identified six metabolites (Sphinganine-1-phosphate, ornithine, phenyllactic acid, inosine, 3-dehydrocarnitine, and hypoxanthine) that were significantly different in $\mathrm{AD}$ patients compared to $\mathrm{CN}$. Three of these metabolites (sphinganine-1-phosphate, ornithine, and phenyllactic acid) were strong predictors of $\mathrm{AD}$ (predictive accuracy; area under curve $=0.998)(70)$. Ornithine is an intermediate metabolite of polyamine metabolism, which was affected in the plasma of AD patients (62). These results demonstrate the potential use of metabolomics to develop salivary biomarkers capable of diagnosing $\mathrm{AD}$.

\section{METABOLOMICS IN MOUSE MODELS OF AD}

In 1907, Dr. Alois Alzheimer described the first patient with senile plaques and NFTs, which represent the major hallmarks of $\operatorname{AD}(104,105)$. Since the initial description, significant progress has been made to enhance our understanding of $\mathrm{AD}$ mechanisms including the identification of familial gene mutations in APP (106-108), PS1, and PS2 $(109,110)$ implicated in the accumulation of amyloid peptides. While only a very small number of $\mathrm{AD}$ cases are associated with familial mutations, the development of mouse models that express human APP, PS1, and PS2 transgenes significantly expanded the ability to study disease 
mechanisms. Mice can also harbor the human transgene encoding MAPT, which in its hyperphosphorylated state forms NFTs (111). Currently, along with the popular models of FAD including APP (Tg2576), APP/PS1, or 3xTg AD mice, the development of humanized mouse models expressing genetic risk factors, such as APOE $\varepsilon 4$ allele, allows researchers to study mechanisms of late-onset sporadic AD (111-113). Table 3 represents some of the most commonly used mouse models of AD.

Mice have become a common model to study AD since they share $99 \%$ of their genes with humans, have a relatively short life span (approximately 2-3 years), are easy to handle and to house, have a simple reproductive scheme, and can be genetically modified (126). However, while mice carry endogenous genes encoding for APP and tau, they do not naturally develop AD. While the exact reasons for that are unknown, it may be due to the three amino acid difference between human and rodent $A \beta$ or that mice do not live long enough (127). Although there is no single mouse model that recapitulates the complexity of human $\mathrm{AD}$, transgenic mice provide an invaluable resource for studying the effect of individual genetic components on the disease progression and for preclinical validation of experimental therapeutics (114-121). Application of metabolomics confirmed early energetic and metabolic alterations in multiple mouse models of FAD that recapitulate human conditions $(33,57)$. The most recent applications of metabolomics to study metabolic disturbances in biofluids and brain tissue of $\mathrm{AD}$ mouse models are summarized in Table 4.

\section{METABOLIC PROFILING IN BRAIN TISSUE AND BLOOD FROM TRANSGENIC MOUSE MODELS OF AD}

In two consecutive studies, Gonzalez-Dominguez and colleagues used direct infusion MS (DIMS) to explore altered metabolic profiles in APP/PS1 mice compared to non-transgenic (NTG) CN mice $(128,129)$. In the first study, the authors focused on the evaluation of region-specific metabolic changes in the hippocampus, cortex, $\mathrm{CB}$, and olfactory bulbs of male and female mice 6 months of age. The greatest changes in metabolite composition were found in the cortex and hippocampus of $\mathrm{AD}$ compared to NTG mice including the accumulation of fatty acids and alterations in phospholipids and acylcarnitines related to neural membrane degradation and impaired $\beta$-oxidation, respectively (128). In all brain regions examined, levels of the neurotransmitter dopamine were altered in AD compared to NTG mice similar to that observed in $\mathrm{AD}$ patients $(128,138,139)$. The cortex and hippocampus are two regions primarily affected in $\mathrm{AD}$ with high levels of amyloid plaques and NFTs (140). Consistent with this, the authors found the greatest disturbances in the cortex and hippocampus supporting that metabolic alterations are closely linked to neuropathological changes in $\mathrm{AD}(141,142)$. Similar to $\mathrm{AD}$ patients, region-specific changes in fatty acids were detected in postmortem $\mathrm{AD}$ brains (59).

In the second study, Gonzalez-Dominguez and colleagues analyzed serum from APP/PS1 mice using a two-step extraction

TABLE 3 | Common transgenic mouse models of AD utilized in metabolomics studies.

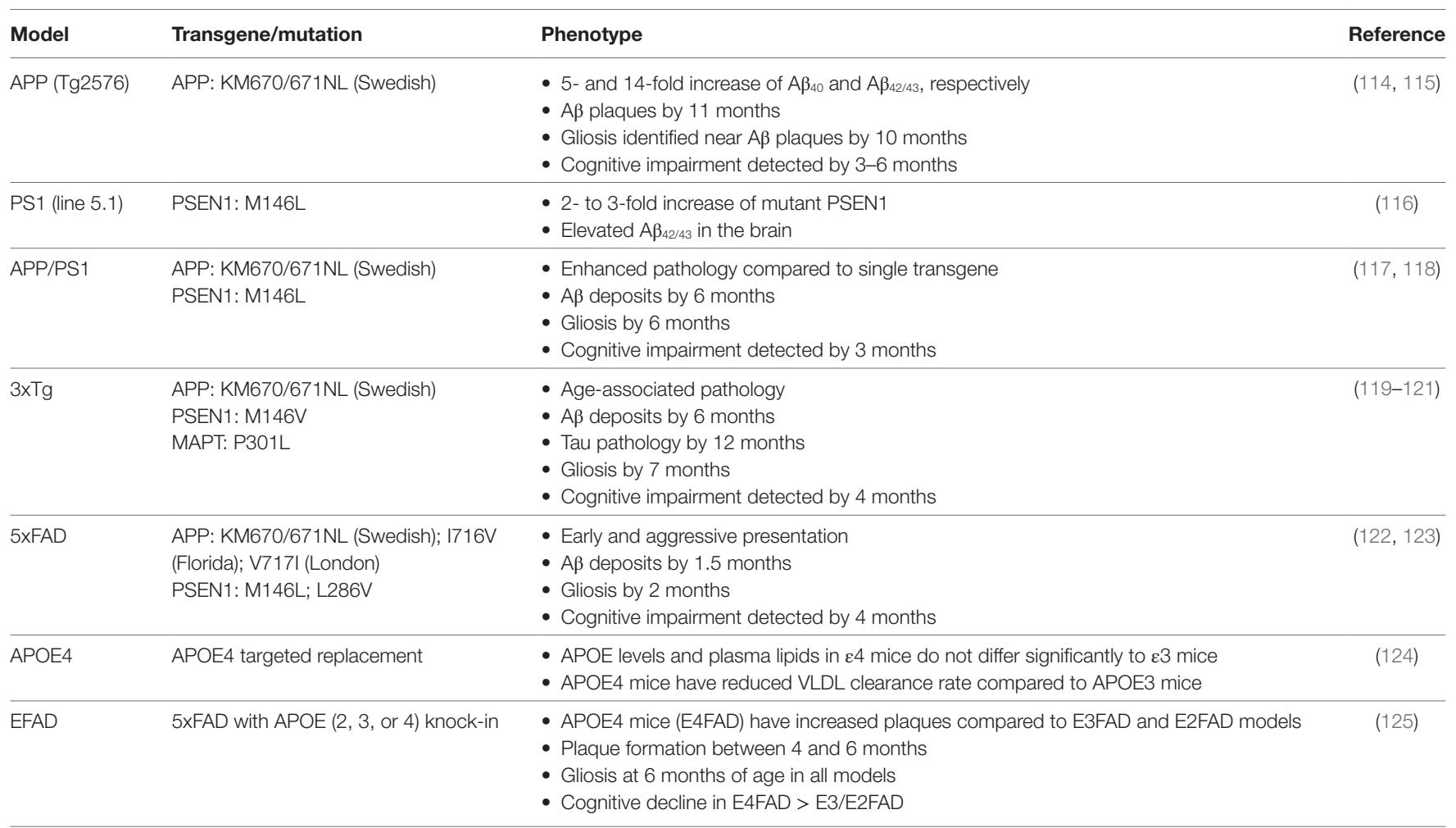

APOE, apolipoprotein E; APP, amyloid precursor protein; FAD, familial Alzheimer's disease; MAPT, microtubule-associated protein tau; PS1/PSEN1, presenilin-1; VLDL, very low density lipoprotein. 
TABLE 4 | Application of metabolomics in samples from AD mouse models.

\begin{tabular}{|c|c|c|c|}
\hline $\begin{array}{l}\text { Analytical } \\
\text { platform }\end{array}$ & Samples & Findings & Reference \\
\hline DIMS & $\begin{array}{l}\text { Brains and plasma from APP/ } \\
\text { PS1 and WT mice }\end{array}$ & $\begin{array}{l}\text { - } \text { APP/PS1 cortex and hippocampus had altered phospholipids and ACs } \\
\text { - APP/PS1 blood serum had significant alterations in eicosanoids (LB4, HEPE, and } \\
\text { prostaglandins) } \\
\text { - Studies suggest altered lipid metabolism and energy utilization in APP/PS1 mice }\end{array}$ & $(128,129)$ \\
\hline $\begin{array}{l}\text { Absolute IDQ p180 } \\
\text { Kit measured by } \\
\text { UPLC-MS }\end{array}$ & $\begin{array}{l}\text { Longitudinal collection } \\
\text { (6-18 months) of APP/PS1 } \\
\text { and WT mouse brains and } \\
\text { plasma }\end{array}$ & $\begin{array}{l}\text { - } 6 \text { months: } \uparrow \text { Arg in brain, } \downarrow \text { Gln and Pro in plasma } \\
\text { - At 6-10 months: } \uparrow \text { polyamines putrescine, spermidine, and spermine in brain and plasma } \\
\text { - } 10-12 \text { months: } \downarrow \text { Thr } \\
\text { - } 12 \text { months: } \downarrow \text { Gln and citrulline in plasma } \\
\text { - Potential temporal disturbance in amino acids and lipid metabolism }\end{array}$ & (130) \\
\hline $\begin{array}{l}\text { Bile acid kit } \\
\text { measured by } \\
\text { LC-MS/MS }\end{array}$ & $\begin{array}{l}\text { Plasma and whole brain tissue } \\
\text { from } 5 \text { APP/PS1 at } 6 \text { and } \\
12 \text { months of age } \\
\text { Plasma and neocortex from } 10 \\
\text { AD and CN patients }\end{array}$ & $\begin{array}{l}\text { - Bile acids are perturbed in AD samples } \\
\text { - Human plasma had } \downarrow \text { CA in AD patients } \\
\text { - APP/PS1 mouse plasma had } \uparrow \text { CA at } 6 \text { months and } \downarrow \text { hyodeoxycholic acid at } 12 \text { months } \\
\text { - Human neocortex had } \downarrow \text { taurocholic acid } \\
\text { - APP/PS1 brain tissue: } 6 \text { months had } \uparrow \text { lithocholic acid and } \downarrow \text { TMCA; } 12 \text { months had } \downarrow \text { TMCA, } \\
\text { CA, } \beta \text {-muricholic acid, } \Omega \text {-muricholic acid, taurocholic acid, and tauroursodeoxycholic acid }\end{array}$ & $(131)$ \\
\hline UHPLC-MS & $\begin{array}{l}\text { Urine from } 30 \mathrm{APP} / \mathrm{PS} 1 \text { and } \\
\mathrm{CN} \text { mice at } 2 \text { months of age }\end{array}$ & $\begin{array}{l}\text { - Identification of potential early biomarkers in urine } \\
\text { - } \uparrow \text { Spermic acid, 2,4-guanidinobutanoic acid, nicotinuric acid, L-isoleucyl-L-proline, L-2,3- } \\
\text { dihydrodipicolinate, 3,4-dihydroxyphenylglycol o-sulfate, } N \text {-acetyl-L-tyrosine, 5-hydroxyindoleacetic } \\
\text { acid, 3-methoxybenzenepropanoic acid, and 3,4-dimethoxyphenylacetic acid } \\
\text { - Dimethylarginine, 1-methyladenosine, citric acid, 5'-deoxyadenosine, } \\
\text { 1-(beta-D-ribofuranosyl)-1,4-dihydronicotinamide, 7-methylinosine, 2-keto-6-acetamidocaproate, } \\
\text { 7-aminomethyl-7-carbaguanine, succinyladenosine, benzaldehyde, urothion, } \\
\text { 6-hydroxy-5-methoxyindole glucuronide, monobutyl phthalate, and tetrahydrocortisol } \\
\text { - Had greatest impact on glyoxylate and dicarboxylate metabolism }\end{array}$ & $(132)$ \\
\hline $\begin{array}{l}\text { Head-space } \\
\text { GC-MS }\end{array}$ & $\begin{array}{l}\text { Urine of } 15 \text { APP mice, } 15 \\
\text { Tg2576 mice, } 9 \text { TgCRND8 } \\
\text { mice, and } 10 \text { APPLd2 mice } \\
\text { and NTG littermates }\end{array}$ & $\begin{array}{l}\text { - } \uparrow \text { Phenylacetone across all three APP mice } \\
\text { - Linear discriminant analysis predicted groups with <16\% error } \\
\text { - Predictive metabolites include 6-hydroxy-6-methyl-3-heptanone, 3-methylcyclopentanone, } \\
\text { 4-methyl-6-hepten-3-one, 1-octen-3-ol, 2-sec-butyl-4,5-dihydrothiazole, acetophenone, } \\
\text { phenylacetone, o-toluidine }\end{array}$ & (133) \\
\hline $\begin{array}{l}\text { LC-MS and } \\
\text { GC-MS }\end{array}$ & $\begin{array}{l}\text { Cortex and plasma from } \\
\text { symptomatic APP/PS1 mice }\end{array}$ & $\begin{array}{l}\text { - CAD-31 was found to be neuroprotective } \\
\text { - CAD-31 in plasma of APP/PS1 mice } \uparrow \text { sphingolipids (glycosyl- } N \text {-stearoyl-sphingosine and } \\
\text { sphingosine-1-phosphate) } \\
\text { - CAD-31 in cortex of APP/PS1 mice } \uparrow \text { monoacylglycerols (1-palmitoylglycerol, 2-palmitoylglycerol, } \\
\text { 2-oleoylglycerol) } \\
\text { - CAD-31 in plasma of control mice } \downarrow \text { long-chain fatty acids (margarate, pentadecanoate, } \\
\text { 10-nonadoconoate), } \uparrow \text { acylcarnitines (C0, C16, C18:1), } \uparrow \text { ketone body } 3 \text {-hydroxybutyrate, } \uparrow \\
\text { sphingolipids (glycosyl- } N \text {-stearoyl-sphingosine, sphinganine-1-phosphate, } \\
\text { sphingosine-1-phosphate, sphinganine) } \\
\text { - CAD-31 in cortex of control mice was similar to plasma }\end{array}$ & $(134)$ \\
\hline HPLC-QTOF-MS & $\begin{array}{l}\text { Plasma from AD-induced } \\
\text { mice (via } A \beta 42 \text { injection) and } \\
\text { controls ( } n=8 \text { per group) }\end{array}$ & $\begin{array}{l}\text { - Breviscapine treatment was neuroprotective in A } \beta \text { injected mice } \\
\text { - Multivariate analysis of breviscapine treated A } \beta \text { mice identified indoleacrylic acid, C16 } \\
\text { sphinganine, LPE (22:6), sulfolithocholic acid, LPC (16:0), PA (22:1/0:0), taurodeoxycholic acid, } \\
\text { and PC (0:0/18:0) } \\
\text { - Phospholipid and cholesterol modulation may be neuroprotective }\end{array}$ & $(135)$ \\
\hline IC-MS/MS & $\begin{array}{l}\text { Primary astrocytes of } 5 x F A D \\
\text { mice from neocorticies of } \\
1 \text { - to } 3 \text {-day-old mice }\end{array}$ & $\begin{array}{l}\text { - Pantethine has anti-inflammatory properties } \\
\text { - AD astrocytes treated with pantethine had improved glycolytic and TCA cycle flux } \\
\text { - Pantethine treatment in AD astrocytes augmented glucose-6-phosphate, glycerol-3-phosphate, } \\
\alpha K G \text {, fumarate, and succinate levels }\end{array}$ & $(136)$ \\
\hline EIS-MS/MS & $\begin{array}{l}\text { BMDMs derived from Trem2 } 2^{-/-} \\
\text {and WT mice }\end{array}$ & $\begin{array}{l}\text { - } \downarrow \text { UDP-glucose, CDP-ethanolamine, glucose-6-phosphate, fructose bisphosphate, citrate, and } \\
\text { succinate } \\
\text { - } \uparrow \text { Indolacetate, glycerol-3-phosphate, malate, and fumarate } \\
\text { - TREM2 deficiency perturbs mTOR signaling and nucleotide, glycolytic, and TCA cycle metabolites } \\
\text { - Cyclone creatine supplement alleviates TREM2 deficiency in BMDMs }\end{array}$ & (137) \\
\hline
\end{tabular}

aKG, aketoglutarate; AD, Alzheimer's disease; Arg, arginine; APP, amyloid precursor protein; BMDMs, bone marrow-derived macrophages; CA, cholic acid; CDP, cytidine diphosphate; CN, control; DIMS, direct infusion mass spectrometry; EIS-MS/MS, electrospray ionization; FAD, familial Alzheimer's disease; GIn, glutamine; GC-MS, gas chromatography-MS; HEPE, hydroxy-eicosapentaenoic acid; HPLC-QTOF-MS, high-performance liquid chromatography quadropole-time-of-flight MS; IC-MS/MS, ion chromatography-MS/MS; LB4, leukotriene B4; LC-MS, liquid chromatography-MS; LPC, lysophosphatidylcholine; LPE, lysophosphatidylethanolamine; MS/MS, tandem mass spectrometry; mTOR, mammalian target of rapamycin; NTG, non-transgenic; PA, phosphatidic acid; PC, phosphatidylcholine; Pro, proline; PS1/PSEN1, presenilin-1; TCA, tricarboxylic acid; Thr, threonine; TMCA, tauromuricholic acid; TREM2, triggering receptor expressed on myeloid cells 2; UDP, uridine diphosphate; UHPLC, UItra high-performance liquid chromatography; UPLC-MS/MS, ultra performance liquid chromatography-MS/MS; WT, wild type. 
method to increase the range of metabolites detected (129). Combined DIMS with electrospray ionization and flow injection atmospheric pressure photoionization MS techniques allowed for a fast comprehensive scan of polar and non-polar metabolites, respectively. The largest alterations in the serum of APP/ PS1 compared to NTG mice were found in levels of eicosanoids including leukotriene B4 (LTB4), hydroxy-eicosapentaenoic acid (HEPE), and prostaglandins (129). Eicosanoids are derived from polyunsaturated fatty acids known for their role in inflammatory and immune responses (143). Consistent with these results, eicosanoids have been linked to neuroinflammation and $\mathrm{AD}$ etiology $(144,145)$. Metabolomics studies in human plasma also identified perturbed fatty acid metabolism (18) further suggesting that APP/PS1 mice recapitulate peripheral metabolic changes associated with the progression of AD in humans.

One of the advantages for studying $\mathrm{AD}$ in transgenic mouse models is the ability to easily collect and analyze longitudinal samples for metabolic changes during various disease stages in respect to amyloid deposition and cognitive function. Pan et al. conducted one of the first longitudinal metabolic profiles using brain tissue and plasma from 6, 8, 10, 12, and 18 months old APP/ PS1 mice relative to NTG controls (130). Longitudinal samples were analyzed using a Biocrates Absolute IDQ p180 Kit measured by UPLC-MS. Metabolic pathway analysis identified perturbed polyamine metabolism in the brain tissue and plasma of APP/ PS1 mice. Additional alterations were detected in essential amino acids, branched-chain amino acids, and the neurotransmitter serotonin. The authors noted that metabolic changes detected in the brain tissue of APP/PS1 mice were observed in the blood 2-4 months later (130). For instance, phospholipids were found most significantly altered in the brain of APP/PS1 mice at 8 months of age with the same alterations detected in blood 4 months later. This suggests a temporal sequence of events where changes in brain metabolites precede those in the blood. The authors determined that group separation between APP/ PS1 and NTG mice based on metabolic signatures was the most pronounced between the ages of 8 and 12 months. In contrast, the brain and blood metabolic profiles between APP/PS1 and NTG mice in the youngest ( 6 months) and oldest (18 months) populations were less clearly separated (130). In the study by Pan and colleagues (130), it is worth noting that over a span of 12 months, the metabolic disturbances in APP/PS1 mice were transient suggesting that increasing $\mathrm{AD}$ pathology has a progressive impact on metabolism. This is in agreement with observations reported by Toledo et al. in the plasma of patients with $\mathrm{AD}$ enrolled in the ADNI study (18). Furthermore, Pan et al. detected increased levels of the polyamines spermine and spermidine at 8 months in the brain tissue and plasma of APP/PS1 mice (130), which is similar to changes identified in our previous study (30) and by others in the plasma of AD patients (62).

\section{METABOLIC PROFILING IN MOUSE AND HUMAN BILE ACIDS}

Primary bile acids are synthesized in the liver and are well known for their role in cholesterol catabolism (146). Bile acid-induced signaling through nuclear receptors and cell surface G-proteins can modulate several metabolic, immune, and inflammatory processes (147). Secretion of bile acids into the intestine results in further modification by gut microbiota, which is thought to influence brain morphology, injury, and stress via the gut-brain axis (148). Increasing evidence implicates bile acids in several neurological diseases including AD (149-151). Feeding APP/ PS1 mice with $0.4 \%$ tauroursodeoxycholic acid for 6 months resulted in decreased levels of $\mathrm{A} \beta$ in the hippocampus and cortex along with increased memory performance (152). Furthermore, therapeutic approaches targeting bile acid metabolism and signaling have shown beneficial effects in several metabolic and neurodegenerative disorders (151, 153-155). Using human and mouse samples, Pan et al. investigated longitudinal changes of bile acids in respect to $\mathrm{AD}$ development (131). Metabolic changes in human postmortem brain tissue (neocortex, $n=10$ ) from confirmed AD cases along with plasma obtained from patients predicted to have $\mathrm{AD}(n=10)$ was compared to age-matched controls. Additionally, the authors profiled whole brain tissue and plasma from APP/PS1 mice at 6 and 12 months of age. The authors quantitated 22 bile acids using the Biocrates Bile Acid Kit analyzed by LC-MS/MS (131). In human plasma, they identified a single bile acid, cholic acid, which was significantly lower in $\mathrm{AD}$ patients compared to controls. Analysis of $\mathrm{AD}$ brain tissue from humans revealed a significant decrease in taurocholic acid (131). Bile acid analysis in the plasma from APP/PS1 mice revealed that cholic acid was significantly higher in 6-month-old mice while hyodeoxycholic acid was decreased in 12-month-old mice compared to NTG controls (131). In APP/PS1 mouse brain tissue, the authors identified two perturbed bile acids at 6 months of age compared to NTG. At 12 months of age, APP/PS1 mice had six bile acids that were significantly altered. Among the altered bile acids, only tauromuricholic acid was decreased in APP/PS1 mice in both age groups (131). A decrease in taurocholic acid was observed in both human AD cortex and APP/PS1 mouse brain tissue (131). Hydrolysis of taurocholic acid yields the nonessential amino acid taurine (156). Transgenic APP/PS1 mice administered taurine via drinking water displayed improved cognition with slightly reduced levels of $A \beta$ in the cortex (157). Taken together, these findings warrant further investigation into the relationship between bile acid perturbations and AD.

\section{METABOLIC PROFILING IN MOUSE URINE}

Yu et al. investigated metabolic changes in the urine of APP/ PS1 transgenic mice prior to cognitive impairment (132). At 2 months of age, the spatial working memory of APP/PS1 mice showed no significant differences when compared to NTG controls (132). However, metabolomics analysis of urine from the 2-month-old mice indicated that several metabolites were differentially regulated in APP/PS1 mice compared to controls. Applying UPLC coupled with quadruple time-of-flight MS, Yu et al. identified 10 metabolites that were significantly upregulated and 14 metabolites that were downregulated in APP/PS1 mice (132). These results suggest that early metabolic changes occur prior to spatial memory and cognitive impairment. Pathway analysis of the dysregulated metabolites allude to perturbations 
in pentose and glucoronate interconversions, glyoxylate and dicarboxylate metabolism, starch and sucrose metabolism, the citrate cycle, arginine and proline metabolism, and tryptophan metabolism early in APP/PS1 mice compared to controls (132). The metabolite 5-hydroxyindoleacetic acid (5-HIAA) was significantly increased in the urine of APP/PS1 mice compared to controls (132). In urine, the concentration of 5-HIAA is routinely used to estimate levels of serotonin in the body (158). Serotonin is a neurotransmitter that can affect cognition, and changes in its levels have been implicated in $\operatorname{AD}(31,159,160)$. Therefore, metabolic analysis of urine from APP/PS1 mice may reflect fluctuations in the brain.

Using GC-MS, levels of volatile metabolites were investigated in the urine from three different transgenic APP mouse models (133). Each mouse model has a distinct pathological time course $(114,161,162)$. The three strains included the Tg2576, TgCRND8, and APPld2 mice, which developed amyloidosis between 3-16, 2-8, and 4-23 months of age, respectively (133). The authors identified seven urine metabolites that discriminated transgenic mice from NTG littermates. Common across all three transgenic models was a disruption in 1-octen-3-ol (octenol) (133), which has previously been implicated in disrupting dopamine homeostasis resulting in neurodegeneration (163). Three additional unique metabolites were identified in Tg2576 mice (2-sec-butyl-4,5-dihydrothiazole, acetophenone, and phenylacetone), one in TgCRND8 mice (4-methyl-6-hepten-3-one), and two in APPLd2 mice (3-methylcyclopentanone and o-toluidine) (133). While these results identified a common dysregulated metabolite (octenol) in the urine of all three transgenic mouse models, their respective unique signatures further suggest that varying $\mathrm{A} \beta$ pathology has a gradual impact on the metabolome.

\section{APPLICATION OF METABOLOMICS TO MONITOR THERAPEUTIC EFFICACY}

To date, there are no disease-modifying strategies for $\mathrm{AD}$. Multiple clinical trials designed to reduce $\mathrm{A} \beta$ production or clearance have failed (164). One explanation is that most treatments were administered at a late stage of the disease when irreversible damage has already occurred. There is a clear need for more accurate and early diagnosis of people who are on the trajectory to develop $\mathrm{AD}$ so clinical trials can be conducted in individuals where the course of the disease could be modified or reversed. Additionally, there is a need to monitor therapeutic efficacy of experimental treatments. While some clinical trials now include the collection of biofluids to monitor therapeutic outcomes using metabolomics, these results have not been published yet. Several recent studies, however, have used metabolomics to monitor efficacy of new therapeutic approaches in preclinical transgenic mouse models of AD.

Schubert and colleagues developed a drug that has neurogenic and neuroprotective properties $(134,165,166)$. The drug derives from a hybrid of curcumin and cyclohexyl-bisphenol A $(166,167)$. A derivative of this compound, CAD-31, showed potent neuroprotection and memory enhancing properties in AD mouse models (165). In a follow-up study, Daugherty and colleagues studied the effects CAD-31 on the metabolome of AD mice (134). Transgenic female APP/PS1 mice were administered CAD-31 starting at 10 months of age for 3 months. Cortex brain tissue and plasma samples from CAD-31 treated and untreated mice were analyzed using non-targeted GC-MS and LC-MS (134). Metabolomics analysis in plasma of $\mathrm{AD}$ mice demonstrated that sphingolipids were significantly altered by CAD-31 treatment, while ketone bodies, long-chain fatty acids, acylcarnitines, and sphingolipids were affected in $\mathrm{CN}$ mice (134). In the cortex of CAD-31-treated APP/PS1 mice, the most significantly altered metabolites were monoacylglycerols including 1- and 2-palmitoylglycerol and 2-oleoylglycerol (134). Decreased brain glucose utilization is a well-characterized early metabolic phenotype detected in AD patients. This brain hypometabolism indicates the requirement for the use of alternative fuel sources in order to maintain neuronal function $(27,168,169)$. The neuroprotective and memory enhancing effects seen in AD mice treated with CAD-31 may, in part, be associated with a metabolic shift toward lipid utilization. Metabolites affected by CAD-31 treatment in WT mice included ketones, acylcarnitines, and acetyl-CoA, which suggest that mitochondrial energetics and lipid metabolism were favorably altered. However, in APP/PS1 mice, only monoacylglycerols were significantly altered by CAD-31 treatment (134). The monoacylglycerol 2-arachidonoylglycerol (2-AG), known for its role in neurotransmission (170), has previously been implicated in the pathogenesis of $\mathrm{AD}$ (171). Hydrolysis of 2-AG by monoacylglycerol lipase results in the formation of arachidonic acid, which is a precursor for the eicosanoids LTB4, HEPE, and prostaglandins (171-174). In line with these findings, Gonzalez-Dominguez and colleagues identified altered levels of LTB4, HEPE, and prostaglandins in the serum of APP/PS1 mice (129). These findings could indicate that modulation of lipid metabolism and monoacylglycerols may be an effective therapeutic strategy to favorably alter cellular energetics and synaptic signaling in $\mathrm{AD}$.

Erigerontis Herba is a traditional Chinese medicine used to treat cardiovascular diseases (175). Scutellarin, a flavone found in Erigerontis Herba, has been shown to prevent $\beta$-amyloid aggregation (176). In an attempt to identify the underlying therapeutic mechanisms of Erigerontis Herba administration, $\mathrm{Xia}$ et al. investigated metabolic changes in $\mathrm{AD}$ mice treated with breviscapine, a drug containing $>85 \%$ scutellarin $(135,175)$. In this study, $\mathrm{AD}$ was induced in mice via unilateral ventricle injection of aggregated $\mathrm{A} \beta 42$ peptides. $\mathrm{AD}$-induced mice displayed decreased learning and memory abilities compared to controls (135). Dose-dependent treatment of AD mice treated with breviscapine showed improved performance in behavior tests compared to untreated controls (135). Plasma from AD mice treated with breviscapine was analyzed using LC-MS metabolomics. The authors identified eight metabolites implicated in lipid metabolism including indoleacrylic acid, C16 sphinganine, lysophosphatidylethanolamine, sulfolithocholic acid, lysophosphatidylcholine, phosphatidic acid, taurodeoxycholic acid, and phosphatidylcholine (135). Consistent with other studies $(66,67$, 131), these results suggest that modulation of lipid metabolism in AD can enhance neuroprotection.

Unbalanced inflammatory mechanisms from several neural cells, including microglia, oligodendrocytes, and astrocytes, are 
thought to contribute to the progression of AD (177). Pantethine, a precursor to vitamin $\mathrm{B} 5$, has previously been shown to alleviate symptoms related to immune and inflammatory responses (178, 179). Furthermore, pantethine has been shown to be beneficial in treating metabolic disorders associated with mitochondrial dysfunction and neurodegeneration (180-182). Using astrocytes from newborn 5xFAD mice, van Gijsel-Bonnello et al. studied early mechanisms of inflammation and metabolic disorder that contribute to $\mathrm{AD}$ (136). The authors evaluated if treatment with pantethine in 5xFAD astrocytes would prevent inflammatory and metabolic dysfunction (136). Non-targeted analysis revealed disturbances in metabolites of the glycolytic pathway (glucose-6-phosphate and glycerol-3-phosphate) and TCA cycle ( $\alpha$ ketoglutarate, fumarate, and succinate) in 5xFAD astrocytes compared to controls (136). Pantethine treatment reduced the extent of alterations seen in 5xFAD astrocytes (136). The authors linked improved glycolytic and TCA cycle flux with nucleotide homeostasis and increased ATP levels (136). Additionally, they reported reduced inflammatory processes in $5 x F A D$ astrocytes treated with pantethine highlighting the benefits of augmenting altered brain energetics early in AD (136).

The protein triggering receptor expressed on myeloid cells 2 (TREM2) is a cell surface receptor known for its role in immune signaling (183). Recent GWAS studies associated a mutation in TREM2 (R47H) with increased risk for AD (184). TREM2 was further shown to be a sensor for lipids associated with $\mathrm{A} \beta$, which is impaired by the $\mathrm{R} 47 \mathrm{H}$ mutation (185). Furthermore, Trem 2 deficiency in $5 x F A D$ mice led to increased A $\beta$ burden (185). Using a combination of transmission electron microscopy and confocal imaging, Ulland et al. observed an increase in autophagic vesicles in microglia from Trem $2^{-/} 5 \mathrm{xFAD}$ mice compared to wild-type mice (137). The authors hypothesized that increased autophagic vesicles may be indicative of metabolic stress mediated, in part, by dysregulation of the mammalian target of rapamycin (mTOR) pathway, which is known for its role in controlling metabolism and autophagy $(137,186)$. Indeed, mTOR signaling was impaired in the microglia of Trem $2^{-1-} 5 x F A D$ mice (137). In a parallel model, using bone marrow-derived macrophages deficient of Trem2, the authors applied electrospray ionization (EIS)-MS/ MS metabolomics to reveal potential mTOR-mediated energetic stress responses (137). In Trem $2^{-1-}$ macrophages, the authors found significant decreases in uridine diphosphate-glucose, cytidine diphosphate-thanolamine, glucose-6-phosphate, fructose bisphosphate, citrate, and succinate accompanied by increases in indolacetate, glycerol-3-phosphate, malate, and fumarate when compared to wild-type cells (137). Their results suggest that TREM 2 deficiency and perturbed mTOR signaling results in marked decreases in nucleotide, glycolytic, and TCA cycle metabolites with an increase in catabolic products of amino acids and phospholipids (137). The authors further investigated whether supplementation with cyclone creatine, known to increase ATP/ADP ratio $(137,187)$, could alleviate metabolic deficiency established in Trem $2^{-/-}$macrophages. Their results demonstrated that bypassing the energetic stress identified in Trem $2^{-/-}$macrophages by supplementation with cyclone creatine improved bioenergetics and mTOR signaling (137). These results intricately demonstrate the capability to identify biomarkers associated with $\mathrm{AD}$ and provide proof of concept for the ability to restore dysfunctional pathways identified using metabolomics.

\section{DISCUSSION}

Recent advances in the field of AD have highlighted the need to identify biomarkers for early disease diagnosis, develop new therapeutic strategies to modify or halt the disease progression, and establish models that provide reliable and strong translational value. The analysis of recent literature demonstrates that metabolomics, sparse in the past, is becoming more frequently utilized in human and animal studies extending the application to various systems including CSF, plasma, brain tissue, cells, urine, and saliva among others. Together with changes in the brain, metabolic alterations are detected in multiple tissues and fluids in $\mathrm{AD}$ patients suggesting a systemic nature of the disease. This underlines the potential utility of metabolomics to study pathophysiological mechanisms in living patients and establish biomarkers using readily available biofluids and tissue (e.g., plasma and skin fibroblasts).

The strength of metabolomics is in the capability of measuring the plethora of metabolites providing a snapshot of an individual's current biological status. Since the metabolome reflects individual's unique genomic, proteomic, and transcriptomic alterations, metabolomics can provide a global system analysis offering greater insight compared to other approaches. Application of metabolomics in animal models of AD demonstrated a significant overlap in the affected pathways identified in humans (Tables 2 and 4). This is of considerable importance providing a justification for the use of transgenic mouse models for translational research. The ability to conduct longitudinal studies assaying metabolic changes simultaneously in the brain tissue and the periphery represents an outstanding advantage of mouse models to define the relationship between preclinical biomarkers of $\mathrm{AD}$ vs clinical signatures. Metabolomics analysis conducted in biological samples of patients with MCI and AD identified metabolic changes associated with preclinical $(18,59$, $60,62,132)$ and clinical $\operatorname{AD}(18,58,61,62,129)$. These findings suggest that metabolomics-based biomarkers could be used to improve disease diagnosis, which will allow to target pathways altered early in $\mathrm{AD}$. As shown in mouse models of $\mathrm{AD}$, monitoring therapeutic efficacy could also provide valuable insight into the mechanistic effects of potential disease-modifying drugs (134-137).

Studies using metabolomics and lipidomics have identified several metabolic pathways altered in $\mathrm{AD}$ including methionine, arginine, and glutamate metabolism, fatty acid biosynthesis and lipid metabolism, and mitochondrial bioenergetics (Tables 2 and 4). However, most of the published studies agreed that lipid metabolism is the most consistently altered pathway in $\mathrm{AD}$ pathogenesis. Toledo et al. performed one of the largest blood-based metabolomics studies in $\mathrm{AD}$ patients to date correlating alterations in sphingomyelins and ether-containing phosphatidylcholines with preclinical biomarker-defined AD stages and symptomatic changes with acylcarnitines, amines, and branched-chain amino acids (18). In line with these results, several other studies identified significantly altered lipids in AD 
(Tables 2 and 4). Specifically, changes in sphingomyelin, an important component of lipid rafts, were associated with early preclinical AD (60). Snowden et al. further demonstrated that changes in UFAs occur in the $\mathrm{CB}$, which is relatively unaffected by $A \beta$ and tau pathologies (59). These results suggested that changes in UFAs might occur early in AD development independently of $A \beta$ and tau accumulation in the brain. Similarly, Legido-Quigley's group observed perturbed levels of fatty acids in the plasma of AD patients including phosphatidylcholines, ChEs, and ceramides, which was further correlated with brain atrophy (63-65). Metabolomics analysis by Pan et al. of plasma and brain tissue from both humans and mice reveled that bile acids, which are important for lipid metabolism, are perturbed in $\mathrm{AD}$ (131). These experiments conducted using metabolomics and lipidomics clearly implicate these metabolites in the pathology of AD.

Taken together, metabolomics and lipidomics profiling has provided strong evidence that multiple factors are involved in the pathology of AD where lipid homeostasis appears to be an essential component. Lipids play a major role in normal biological functions including membrane structure, $\beta$-oxidation, cell signaling, and formation of bile acids. The first report by Alois Alzheimer described altered lipid composition in the brain tissue of $\mathrm{AD}$ patients $(104,105)$. Identification of the APOE $\varepsilon 4$ allele as a major genetic risk factor for sporadic $\mathrm{AD}$ further strengthened the involvement of lipid homeostasis in AD pathogenesis. APOE is known for its primary role in lipid uptake and transport in cells. The allelic variant $\varepsilon 4$ is associated with an increase in levels of toxic $A \beta$ oligomers in the brain (188). In addition to APOE, lipids are also implicated in the regulation of the membranebound proteins associated with AD including APP, BACE1, and the presenilin proteins (189-191). Furthermore, the phosphorylation of tau protein could be influenced by various lipids (192, 193).

While metabolic profiling has provided significant insight into $\mathrm{AD}$ mechanisms, findings can be conflicting and inconsistent between studies. Variability in metabolic profiling arises from several factors including the experimental design, sample processing, platform selection, data analysis, and the accounting for confounders such as medication. For human studies, experimental design is often limited by the availability of samples for the analysis reducing statistical significance. Sometimes samples are not matched by age, sex, and race. Many studies lack the sufficient number of males and females, which can introduce a significant bias by overlooking sex-specific changes. Confounders, such as medications, could further complicate data analysis. However, several additional factors including diet, environment, comorbidities, and whether patients fast prior to sample collection can influence an individual's metabolome and should also be considered. While mice allow us to control for many of these variables, several problems regarding their translational potential still exist. For instance, mice do not naturally develop $\mathrm{AD}$ and require the expression of human transgenes to develop symptoms. While inbreeding reduces variance in mice, this can also produce results that do not reflect a normal population. Equally important in human and mouse studies is the handling and processing of samples. Metabolic changes are dynamic and occur quickly. Therefore, careful considerations are needed to minimize metabolic alterations that could be induced during sample collection and storage. Additionally, regional tissue variation (e.g., hippocampus vs cortex) should be considered. The methodologies utilized for extraction vary depending on the nature of metabolites under investigation (e.g., lipids vs amino acids). Due to their inherent properties, different classes of metabolites require optimized extraction methods, which should be standardized in order to provide a direct comparison between results generated in different laboratories. Irrespective of the analytical platform, internal standards and reference samples are important for data normalization and quality control measurements. Finally, several multivariate statistical models exist to analyze metabolomics data (194). Proper modeling of metabolomics data is necessary to ensure accurate fitting of the data and identification of biomarkers, which is usually validated in a separate study (194). Additional post-analytical tools can be useful in the interpretation of metabolomics data for clinical application. For instance, CLIR (Collaborative Laboratory Integrated Reports; https://clir.mayo.edu/) is a web-based tool designed at the Mayo Clinic that uses multivariate pattern recognition software, which has an integrated database of clinical and laboratory data. This database is used to generate post-analytical tools capable of evaluating metabolite ratios that may discriminate between various conditions (e.g., $\mathrm{AD}$ vs healthy controls). The CLIR software combines multiple parameters to produce a single score that reflects the probability of having a particular condition. Using complementary analytical approaches will likely enhance the identification and accuracy of metabolic AD biomarkers and their application in the clinic.

\section{CONCLUSION}

A majority of our knowledge of the molecular mechanisms of $\mathrm{AD}$ has derived from the identification of key genes involved in the etiology and pathology of the disease. These genes include APP, PSEN1, and PSEN2 associated with FAD. However, the majority of $\mathrm{AD}$ cases are sporadic with no direct genetic cause and only associated with a few identified risk factors such as the APOE $\varepsilon 4$ allele and TREM2 variants (195). Application of current diagnostic tools strongly suggests that metabolic alterations contribute to early disease mechanisms. The identification of several metabolic networks, including lipid and amino acid metabolism, and metabolic pathways involved in glucose and energy substrate utilization provides insights into potential disease mechanism and therapeutic targets. These findings together with the identification of additional risk factors for $\mathrm{AD}$, such as type 2 diabetes, strengthen the notion that AD is a metabolic disorder (196-200). Metabolomics profiling coupled to pathway analysis could aid in the understanding of the underlying disease mechanisms leading to the development of novel blood-based biomarkers for the diagnosis, prognosis, and monitoring therapeutic efficacy.

\section{AUTHOR CONTRIBUTIONS}

All authors listed have made a substantial, direct, and intellectual contribution to the work and approved it for publication. 


\section{FUNDING}

Research reported in this publication was supported by the National Institute on Aging of the National Institutes of Health under Award AG55549 (to ET). The content is solely

\section{REFERENCES}

1. Lane CA, Hardy J, Schott JM. Alzheimer's disease. Eur J Neurol (2017) 25:59-70. doi:10.1111/ene.13439

2. Bertram L, Tanzi RE. Thirty years of Alzheimer's disease genetics: the implications of systematic meta-analyses. Nat Rev Neurosci (2008) 9(10):768-78. doi:10.1038/nrn2494

3. Hardy JA, Higgins GA. Alzheimer's disease: the amyloid cascade hypothesis. Science (1992) 256(5054):184-5. doi:10.1126/science.1566067

4. Hardy J, Selkoe DJ. The amyloid hypothesis of Alzheimer's disease: progress and problems on the road to therapeutics. Science (2002) 297(5580):353-6. doi:10.1126/science.1072994

5. Huang Y, Mucke L. Alzheimer mechanisms and therapeutic strategies. Cell (2012) 148(6):1204-22. doi:10.1016/j.cell.2012.02.040

6. Haass C, Kaether C, Thinakaran G, Sisodia S. Trafficking and proteolytic processing of APP. Cold Spring Harb Perspect Med (2012) 2(5):a006270. doi:10.1101/cshperspect.a006270

7. Liu CC, Kanekiyo T, Xu H, Bu G. Apolipoprotein E and Alzheimer disease: risk, mechanisms and therapy. Nat Rev Neurol (2013) 9(2):106-18. doi:10.1038/nrneurol.2012.263

8. Alzheimer's Association. Genetic Testing. (2014). Available from: http://alz. org

9. Burke SL, Maramaldi P, Cadet T, Kukull W. Associations between depression, sleep disturbance, and apolipoprotein E in the development of Alzheimer's disease: dementia. Int Psychogeriatr (2016) 28(9):1409-24. doi:10.1017/ S1041610216000405

10. Alzheimer's Association. Alzheimer's Disease Facts and Figures. (2017). Available from: http://alz.org/facts

11. Altmann A, Tian L, Henderson VW, Greicius MD. Alzheimer's disease neuroimaging initiative I. Sex modifies the APOE-related risk of developing Alzheimer disease. Ann Neurol (2014) 75(4):563-73. doi:10.1002/ana.24135

12. Xing Y, Tang Y, Jia J.Sex differences in neuropsychiatric symptoms of Alzheimer's disease: the modifying effect of apolipoprotein E epsilon4 status. Behav Neurol (2015) 2015:275256. doi:10.1155/2015/275256

13. Cummings JL, Morstorf T, Zhong K. Alzheimer's disease drug-development pipeline: few candidates, frequent failures. Alzheimers Res Ther (2014) 6(4):37. doi:10.1186/alzrt269

14. Pimplikar SW, Nixon RA, Robakis NK, Shen J, Tsai LH. Amyloidindependent mechanisms in Alzheimer's disease pathogenesis. JNeurosci (2010) 30(45):14946-54. doi:10.1523/JNEUROSCI.4305-10.2010

15. Tonnies E, Trushina E. Oxidative stress, synaptic dysfunction, and Alzheimer's disease. J Alzheimers Dis (2017) 57(4):1105-21. doi:10.3233/JAD-161088

16. Pagani M, Nobili F, Morbelli S, Arnaldi D, Giuliani A, Oberg J, et al. Early identification of MCI converting to AD: a FDG PET study. Eur J Nucl Med Mol Imaging (2017) 44(12):2042-52. doi:10.1007/s00259-017-3761-x

17. Patel L, Grossberg GT. Combination therapy for Alzheimer's disease. Drugs Aging (2011) 28(7):539-46. doi:10.2165/11591860-000000000-00000

18. Toledo JB, Arnold M, Kastenmuller G, Chang R, Baillie RA, Han X, et al. Metabolic network failures in Alzheimer's disease - a biochemical road map. Alzheimers Dement (2017) 13(9):965-84. doi:10.1016/j.jalz.2017.01.020

19. Nemutlu E, Zhang S, Juranic NO, Terzic A, Macura S, Dzeja P. 18O-assisted dynamic metabolomics for individualized diagnostics and treatment of human diseases. Croat Med J (2012) 53(6):529-34. doi:10.3325/ cmj.2012.53.529

20. Oliver SG, Winson MK, Kell DB, Baganz F. Systematic functional analysis of the yeast genome. Trends Biotechnol (1998) 16(9):373-8. doi:10.1016/ S0167-7799(98)01214-1

21. Flicker C, Ferris SH, Reisberg B. Mild cognitive impairment in the elderly: predictors of dementia. Neurology (1991) 41(7):1006-9. doi:10.1212/ WNL.41.7.1006 the responsibility of the authors and does not necessarily represent the official views of the National Institutes of Health. This work was also supported by the grants from the Mayo Clinic Center for Multiple Sclerosis and Autoimmune Neurology (to ET).

22. Kidd PM. Alzheimer's disease, amnestic mild cognitive impairment, and age-associated memory impairment: current understanding and progress toward integrative prevention. Altern Med Rev (2008) 13(2):85-115.

23. Mosconi L, Andrews RD, Matthews DC. Comparing brain amyloid deposition, glucose metabolism, and atrophy in mild cognitive impairment with and without a family history of dementia. J Alzheimers Dis (2013) 35(3):509-24. doi:10.3233/JAD-121867

24. Mosconi L, Pupi A, De Leon MJ. Brain glucose hypometabolism and oxidative stress in preclinical Alzheimer's disease. Ann N Y Acad Sci (2008) 1147:180-95. doi:10.1196/annals. 1427.007

25. Mergenthaler P, Lindauer U, Dienel GA, Meisel A. Sugar for the brain: the role of glucose in physiological and pathological brain function. Trends Neurosci (2013) 36(10):587-97. doi:10.1016/j.tins.2013.07.001

26. Heininger K. A unifying hypothesis of Alzheimer's disease. IV. Causation and sequence of events. Rev Neurosci (2000) 11:213-328. doi:10.1515/ REVNEURO.2000.11.S1.213

27. Klosinski L, Yao J, Yin F, Fonteh A, Harrington M, Christensen T, et al. White matter lipids as a ketogenic fuel supply in aging female brain: implications for Alzheimer's disease. EBioMedicine (2015) 2(12):1888-904. doi:10.1016/j. ebiom.2015.11.002

28. Ding F, Yao J, Rettberg JR, Chen S, Brinton RD. Early decline in glucose transport and metabolism precedes shift to ketogenic system in female aging and Alzheimer's mouse brain: implication for bioenergetic intervention. PLoS One (2013) 8(11):e79977. doi:10.1371/journal.pone.0079977

29. Koppel SJ, Swerdlow RH. Neuroketotherapeutics: a modern review of a century-old therapy. Neurochem Int (2017). doi:10.1016/j.neuint.2017.05.019

30. Trushina E, Dutta T, Persson XM, Mielke MM, Petersen RC. Identification of altered metabolic pathways in plasma and CSF in mild cognitive impairment and Alzheimer's disease using metabolomics. PLoS One (2013) 8(5):e63644. doi:10.1371/journal.pone.0063644

31. Kaddurah-Daouk R, Zhu H, Sharma S, Bogdanov M, Rozen SG, Matson W, et al. Alterations in metabolic pathways and networks in Alzheimer's disease. Transl Psychiatry (2013) 3:e244. doi:10.1038/tp.2013.18

32. Han X, Rozen S, Boyle SH, Hellegers C, Cheng H, Burke JR, et al. Metabolomics in early Alzheimer's disease: identification of altered plasma sphingolipidome using shotgun lipidomics. PLoS One (2011) 6(7):e21643. doi:10.1371/journal.pone.0021643

33. Trushina E, Nemutlu E, Zhang S, Christensen T, Camp J, Mesa J, et al. Defects in mitochondrial dynamics and metabolomic signatures of evolving energetic stress in mouse models of familial Alzheimer's disease. PLoS One (2012) 7(2):e32737. doi:10.1371/journal.pone.0032737

34. Godyn J, Jonczyk J, Panek D, Malawska B. Therapeutic strategies for Alzheimer's disease in clinical trials. Pharmacol Rep (2016) 68(1):127-38. doi:10.1016/j.pharep.2015.07.006

35. Patti GJ, Yanes O, Siuzdak G. Innovation: metabolomics: the apogee of the omics trilogy. Nat Rev Mol Cell Biol (2012) 13(4):263-9. doi:10.1038/ nrm3314

36. Charidemou E, Ashmore T, Griffin JL. The use of stable isotopes in the study of human pathophysiology. Int J Biochem Cell Biol (2017) 93:102-9. doi:10.1016/j.biocel.2017.07.012

37. Triebl A, Trotzmuller M, Hartler J, Stojakovic T, Kofeler HC. Lipidomics by ultrahigh performance liquid chromatography-high resolution mass spectrometry and its application to complex biological samples. J Chromatogr B Analyt Technol Biomed Life Sci (2017) 1053:72-80. doi:10.1016/j. jchromb.2017.03.027

38. Wishart DS. Current progress in computational metabolomics. Brief Bioinform (2007) 8(5):279-93. doi:10.1093/bib/bbm030

39. Markley JL, Bruschweiler R, Edison AS, Eghbalnia HR, Powers R, Raftery D, et al. The future of NMR-based metabolomics. Curr Opin Biotechnol (2017) 43:34-40. doi:10.1016/j.copbio.2016.08.001 
40. Wishart DS, Jewison T, Guo AC, Wilson M, Knox C, Liu Y, et al. HMDB 3.0 - the human metabolome database in 2013. Nucleic Acids Res (2013) 41(Database issue):D801-7. doi:10.1093/nar/gks1065

41. Smolinska A, Blanchet L, Buydens LM, Wijmenga SS. NMR and pattern recognition methods in metabolomics: from data acquisition to biomarker discovery: a review. Anal Chim Acta (2012) 750:82-97. doi:10.1016/j. aca.2012.05.049

42. Jansson J, Willing B, Lucio M, Fekete A, Dicksved J, Halfvarson J, et al. Metabolomics reveals metabolic biomarkers of Crohn's disease. PLoS One (2009) 4(7):e6386. doi:10.1371/journal.pone.0006386

43. Kentgens AP, Bart J, van Bentum PJ, Brinkmann A, van Eck ER, Gardeniers JG, et al. High-resolution liquid- and solid-state nuclear magnetic resonance of nanoliter sample volumes using microcoil detectors. J Chem Phys (2008) 128(5):052202. doi:10.1063/1.2833560

44. Felli IC, Brutscher B. Recent advances in solution NMR: fast methods and heteronuclear direct detection. Chemphyschem (2009) 10(9-10):1356-68. doi:10.1002/cphc.200900133

45. Garcia A, Barbas C. Gas chromatography-mass spectrometry (GC-MS)-based metabolomics. Methods Mol Biol (2011) 708:191-204. doi:10.1007/978-1-61737-985-7_11

46. Trushina E. LC-MS-based metabolomics in understanding the mechanisms of Alzheimer's disease and biomarker discovery. In: Han J, Parker CE, Borchers $\mathrm{CH}$, editors. Advanced LC-MS Applications in Metabolomics. London, UK: Future Science (2015). p. 40-57.

47. Zhou B, Xiao JF, Tuli L, Ressom HW. LC-MS-based metabolomics. Mol Biosyst (2012) 8(2):470-81. doi:10.1039/clmb05350g

48. Nassar AF, Wu T, Nassar SF, Wisnewski AV. UPLC-MS for metabolomics: a giant step forward in support of pharmaceutical research. Drug Discov Today (2017) 22(2):463-70. doi:10.1016/j.drudis.2016.11.020

49. Sun X, Lin L, Liu X, Zhang F, Chi L, Xia Q, et al. Capillary electrophoresis-mass spectrometry for the analysis of heparin oligosaccharides and low molecular weight heparin. Anal Chem (2016) 88(3):1937-43. doi:10.1021/ acs.analchem.5b04405

50. Baker MJ, Trevisan J, Bassan P, Bhargava R, Butler HJ, Dorling KM, et al. Using Fourier transform IR spectroscopy to analyze biological materials. Nat Protoc (2014) 9(8):1771-91. doi:10.1038/nprot.2014.110

51. Ghaste M, Mistrik R, Shulaev V. Applications of Fourier transform ion cyclotron resonance (FT-ICR) and orbitrap based high resolution mass spectrometry in metabolomics and lipidomics. Int J Mol Sci (2016) 17(6):E816. doi:10.3390/ijms17060816

52. Bedair M, Sumner LW. Current and emerging mass-spectrometry technologies for metabolomics. Trends Anal Chem (2008) 27(3):238-50. doi:10.1016/j. trac.2008.01.006

53. Sellick CA, Knight D, Croxford AS, Maqsood AR, Stephens GM, Goodacre R, et al. Evaluation of extraction processes for intracellular metabolite profiling of mammalian cells: matching extraction approaches to cell type and metabolite targets. Metabolomics (2010) 6(3):427-38. doi:10.1007/ s11306-010-0216-9

54. Snyder HM, Carrillo MC, Grodstein F, Henriksen K, Jeromin A, Lovestone S, et al. Developing novel blood-based biomarkers for Alzheimer's disease. Alzheimers Dement (2014) 10(1):109-14. doi:10.1016/j.jalz.2013.10.007

55. Galasko D, Golde TE. Biomarkers for Alzheimer's disease in plasma, serum and blood - conceptual and practical problems. Alzheimers Res Ther (2013) 5(2):10. doi:10.1186/alzrt164

56. McKhann G, Drachman D, Folstein M, Katzman R, Price D, Stadlan EM. Clinical diagnosis of Alzheimer's disease: report of the NINCDS-ADRDA Work Group under the auspices of Department of Health and Human Services Task Force on Alzheimer's Disease. Neurology (1984) 34(7):939-44. doi:10.1212/WNL.34.7.939

57. Trushina E, Mielke MM. Recent advances in the application of metabolomics to Alzheimer's disease. Biochim Biophys Acta (2014) 1842(8):1232-9. doi:10.1016/j.bbadis.2013.06.014

58. Paglia G, Stocchero M, Cacciatore S, Lai S, Angel P, Alam MT, et al. Unbiased metabolomic investigation of Alzheimer's disease brain points to dysregulation of mitochondrial aspartate metabolism. J Proteome Res (2016) 15(2):608-18. doi:10.1021/acs.jproteome.5b01020

59. Snowden SG, Ebshiana AA, Hye A, An Y, Pletnikova O, O’Brien R, et al. Association between fatty acid metabolism in the brain and Alzheimer disease neuropathology and cognitive performance: a nontargeted metabolomic study. PLoS Med (2017) 14(3):e1002266. doi:10.1371/journal.pmed.1002266

60. Koal T, Klavins K, Seppi D, Kemmler G, Humpel C. Sphingomyelin $\mathrm{SM}(\mathrm{d} 18: 1 / 18: 0)$ is significantly enhanced in cerebrospinal fluid samples dichotomized by pathological amyloid-beta42, tau, and phospho-tau-181 levels. J Alzheimers Dis (2015) 44(4):1193-201. doi:10.3233/JAD-142319

61. Guiraud SP, Montoliu I, Da Silva L, Dayon L, Galindo AN, Corthesy J, et al. High-throughput and simultaneous quantitative analysis of homocysteine-methionine cycle metabolites and co-factors in blood plasma and cerebrospinal fluid by isotope dilution LC-MS/MS. Anal Bioanal Chem (2017) 409(1):295-305. doi:10.1007/s00216-016-0003-1

62. Graham SF, Chevallier OP, Elliott CT, Holscher C, Johnston J, McGuinness B, et al. Untargeted metabolomic analysis of human plasma indicates differentially affected polyamine and L-arginine metabolism in mild cognitive impairment subjects converting to Alzheimer's disease. PLoS One (2015) 10(3):e0119452. doi:10.1371/journal.pone.0119452

63. Proitsi P, Kim M, Whiley L, Pritchard M, Leung R, Soininen H, et al. Plasma lipidomics analysis finds long chain cholesteryl esters to be associated with Alzheimer's disease. Transl Psychiatry (2015) 5:e494. doi:10.1038/tp.2014.127

64. Kim M, Nevado-Holgado A, Whiley L, Snowden SG, Soininen H, Kloszewska I, et al. Association between plasma ceramides and phosphatidylcholines and hippocampal brain volume in late onset Alzheimer's disease. J Alzheimers Dis (2017) 60(3):809-17. doi:10.3233/JAD-160645

65. Proitsi P, Kim M, Whiley L, Simmons A, Sattlecker M, Velayudhan L, et al. Association of blood lipids with Alzheimer's disease: a comprehensive lipidomics analysis. Alzheimers Dement (2017) 13(2):140-51. doi:10.1016/j. jalz.2016.08.003

66. Mapstone M, Cheema AK, Fiandaca MS, Zhong X, Mhyre TR, Macarthur LH, et al. Plasma phospholipids identify antecedent memory impairment in older adults. Nat Med (2014) 20(4):415-8. doi:10.1038/ nm.3466

67. Fiandaca MS, Zhong X, Cheema AK, Orquiza MH, Chidambaram S, Tan MT, et al. Plasma 24-metabolite panel predicts preclinical transition to clinical stages of Alzheimer's disease. Front Neurol (2015) 6:237. doi:10.3389/ fneur.2015.00237

68. Mapstone M, Lin F, Nalls MA, Cheema AK, Singleton AB, Fiandaca MS, et al. What success can teach us about failure: the plasma metabolome of older adults with superior memory and lessons for Alzheimer's disease. Neurobiol Aging (2017) 51:148-55. doi:10.1016/j.neurobiolaging.2016.11.007

69. Yilmaz A, Geddes T, Han B, Bahado-Singh RO, Wilson GD, Imam K, et al. Diagnostic biomarkers of Alzheimer's disease as identified in saliva using 1H NMR-based metabolomics. J Alzheimers Dis (2017) 58(2):355-9. doi:10.3233/JAD-161226

70. Liang Q, Liu H, Zhang T, Jiang Y, Xing H, Zhang A-H. Metabolomics-based screening of salivary biomarkers for early diagnosis of Alzheimer's disease. RSC Adv (2015) 5(116):96074-9. doi:10.1039/C5RA19094K

71. Moffett JR, Ross B, Arun P, Madhavarao CN, Namboodiri AM. $N$-Acetylaspartate in the CNS: from neurodiagnostics to neurobiology. Prog Neurobiol (2007) 81(2):89-131. doi:10.1016/j.pneurobio.2006.12.003

72. Hur JY, Welander H, Behbahani H, Aoki M, Franberg J, Winblad B, et al. Active gamma-secretase is localized to detergent-resistant membranes in human brain. FEBS J (2008) 275(6):1174-87. doi:10.1111/j.1742-4658.2008. 06278.x

73. Fontecave M, Atta M, Mulliez E. S-Adenosylmethionine: nothing goes to waste. Trends Biochem Sci (2004) 29(5):243-9. doi:10.1016/j.tibs.2004.03.007

74. Skovierova H, Vidomanova E, Mahmood S, Sopkova J, Drgova A, Cervenova $\mathrm{T}$, et al. The molecular and cellular effect of homocysteine metabolism imbalance on human health. Int J Mol Sci (2016) 17(10):E1733. doi:10.3390/ijms17101733

75. Ravaglia G, Forti P, Maioli F, Martelli M, Servadei L, Brunetti N, et al. Homocysteine and folate as risk factors for dementia and Alzheimer disease. Am J Clin Nutr (2005) 82(3):636-43.

76. Obeid R, Schadt A, Dillmann U, Kostopoulos P, Fassbender K, Herrmann W. Methylation status and neurodegenerative markers in Parkinson disease. Clin Chem (2009) 55(10):1852-60. doi:10.1373/clinchem.2009.125021

77. Tapia-Rojas C, Lindsay CB, Montecinos-Oliva C, Arrazola MS, Retamales RM, Bunout $\mathrm{D}$, et al. Is L-methionine a trigger factor for Alzheimer's-like neurodegeneration? Changes in Abeta oligomers, tau phosphorylation, synaptic 
proteins, Wnt signaling and behavioral impairment in wild-type mice. Mol Neurodegener (2015) 10:62. doi:10.1186/s13024-015-0057-0

78. Lunnon K, Smith R, Hannon E, De Jager PL, Srivastava G, Volta M, et al. Methylomic profiling implicates cortical deregulation of ANK1 in Alzheimer's disease. Nat Neurosci (2014) 17(9):1164-70. doi:10.1038/nn.3782

79. Bakulski KM, Dolinoy DC, Sartor MA, Paulson HL, Konen JR, Lieberman AP, et al. Genome-wide DNA methylation differences between late-onset Alzheimer's disease and cognitively normal controls in human frontal cortex. JAlzheimers Dis (2012) 29(3):571-88. doi:10.3233/ JAD-2012-111223

80. De Jager PL, Srivastava G, Lunnon K, Burgess J, Schalkwyk LC, Yu L, et al. Alzheimer's disease: early alterations in brain DNA methylation at ANK1, BIN1, RHBDF2 and other loci. Nat Neurosci (2014) 17(9):1156-63. doi:10.1038/nn.3786

81. Skinner J, Carvalho JO, Potter GG, Thames A, Zelinski E, Crane PK, et al. Alzheimer's disease neuroimaging I. The Alzheimer's Disease Assessment Scale-Cognitive-Plus (ADAS-Cog-Plus): an expansion of the ADAS-Cog to improve responsiveness in MCI. Brain Imaging Behav (2012) 6(4):489-501. doi:10.1007/s11682-012-9166-3

82. Jack CR Jr, Holtzman DM. Biomarker modeling of Alzheimer's disease. Neuron (2013) 80(6):1347-58. doi:10.1016/j.neuron.2013.12.003

83. Davatzikos C, Bhatt P, Shaw LM, Batmanghelich KN, Trojanowski JQ. Prediction of MCI to AD conversion, via MRI, CSF biomarkers, and pattern classification. Neurobiol Aging (2011) 32(12):2322.e19-27. doi:10.1016/j. neurobiolaging.2010.05.023

84. Bender DA. The metabolism of "surplus" amino acids. Br J Nutr (2012) 108(Suppl 2):S113-21. doi:10.1017/S0007114512002292

85. Vural H, Sirin B, Yilmaz N, Eren I, Delibas N. The role of arginine-nitric oxide pathway in patients with Alzheimer disease. Biol Trace Elem Res (2009) 129(1-3):58-64. doi:10.1007/s12011-008-8291-8

86. Maxwell AJ, Anderson B, Zapien MP, Cooke JP. Endothelial dysfunction in hypercholesterolemia is reversed by a nutritional product designed to enhance nitric oxide activity. Cardiovasc Drugs Ther (2000) 14(3):309-16. doi:10.1023/A:1007886725480

87. Esch F, Lin KI, Hills A, Zaman K, Baraban JM, Chatterjee S, et al. Purification of a multipotent antideath activity from bovine liver and its identification as arginase: nitric oxide-independent inhibition of neuronal apoptosis. J Neurosci (1998) 18(11):4083-95.

88. Becker-Catania SG, Gregory TL, Yang Y, Gau CL, de Vellis J, Cederbaum SD, et al. Loss of arginase I results in increased proliferation of neural stem cells. J Neurosci Res (2006) 84(4):735-46. doi:10.1002/jnr.20964

89. Kan MJ, Lee JE, Wilson JG, Everhart AL, Brown CM, Hoofnagle AN, et al. Arginine deprivation and immune suppression in a mouse model of Alzheimer's disease. J Neurosci (2015) 35(15):5969-82. doi:10.1523/ JNEUROSCI.4668-14.2015

90. Minois N, Carmona-Gutierrez D, Madeo F. Polyamines in aging and disease. Aging (2011) 3(8):716-32. doi:10.18632/aging.100361

91. Williams K, Dawson VL, Romano C, Dichter MA, Molinoff PB. Characterization of polyamines having agonist, antagonist, and inverse agonist effects at the polyamine recognition site of the NMDA receptor. Neuron (1990) 5(2):199-208. doi:10.1016/0896-6273(90)90309-4

92. Ito K, Makino M, Okado K, Tomita T. Memantine inhibits beta-amyloid aggregation and disassembles preformed beta-amyloid aggregates. Biochem Biophys Res Commun (2017) 493(1):158-63. doi:10.1016/j.bbrc.2017. 09.058

93. Gonzalez-Dominguez R, Garcia-Barrera T, Gomez-Ariza JL. Combination of metabolomic and phospholipid-profiling approaches for the study of Alzheimer's disease. JProteomics (2014) 104:37-47. doi:10.1016/j. jprot.2014.01.014

94. Whiley L, Sen A, Heaton J, Proitsi P, Garcia-Gomez D, Leung R, et al. Evidence of altered phosphatidylcholine metabolism in Alzheimer's disease. Neurobiol Aging (2014) 35(2):271-8. doi:10.1016/j.neurobiolaging.2013. 08.001

95. Di Paolo G, Kim TW. Linking lipids to Alzheimer's disease: cholesterol and beyond. Nat Rev Neurosci (2011) 12(5):284-96. doi:10.1038/nrn3012

96. Morgado I, Garvey M. Lipids in Amyloid-beta processing, aggregation, and toxicity. Adv Exp Med Biol (2015) 855:67-94. doi:10.1007/978-3-31917344-3_3
97. Lim WL, Martins IJ, Martins RN. The involvement of lipids in Alzheimer's disease. JGenet Genomics (2014) 41(5):261-74. doi:10.1016/j.jgg.2014. 04.003

98. Sibal L, Agarwal SC, Home PD, Boger RH. The role of asymmetric dimethylarginine (ADMA) in endothelial dysfunction and cardiovascular disease. Curr Cardiol Rev (2010) 6(2):82-90. doi:10.2174/157340310791162659

99. Park NJ, Zhou H, Elashoff D, Henson BS, Kastratovic DA, Abemayor E, et al. Salivary microRNA: discovery, characterization, and clinical utility for oral cancer detection. Clin Cancer Res (2009) 15(17):5473-7. doi:10.1158/10780432.CCR-09-0736

100. Gorr SU. Antimicrobial peptides in periodontal innate defense. Front Oral Biol (2012) 15:84-98. doi:10.1159/000329673

101. Denny P, Hagen FK, Hardt M, Liao L, Yan W, Arellanno M, et al. The proteomes of human parotid and submandibular/sublingual gland salivas collected as the ductal secretions. J Proteome Res (2008) 7(5):1994-2006. doi:10.1021/pr700764j

102. Takeda I, Stretch C, Barnaby P, Bhatnager K, Rankin K, Fu H, et al. Understanding the human salivary metabolome. NMR Biomed (2009) 22(6):577-84. doi:10.1002/nbm.1369

103. Loo JA, Yan W, Ramachandran P, Wong DT. Comparative human salivary and plasma proteomes. JDent Res (2010) 89(10):1016-23. doi:10.1177/0022034510380414

104. Strassnig M, Ganguli M. About a peculiar disease of the cerebral cortex: Alzheimer's original case revisited. Psychiatry (Edgmont) (2005) 2(9):30-3.

105. Alzheimer A. Über eine eigenartige Erkrankung der Hirnrinde. Vortrag in der Versammlung Südwestdeutscher Irrenärzte in Tübingen am 3. Allg $Z$ Psychiatr Psych Gerichtl Med (1907) 1907:146-8.

106. Kang J, Lemaire HG, Unterbeck A, Salbaum JM, Masters CL, Grzeschik KH, et al. The precursor of Alzheimer's disease amyloid A4 protein resembles a cell-surface receptor. Nature (1987) 325(6106):733-6. doi:10.1038/ $325733 \mathrm{a} 0$

107. Glenner GG, Wong CW. Alzheimer's disease and Down's syndrome: sharing of a unique cerebrovascular amyloid fibril protein. Biochem Biophys Res Commun (1984) 122(3):1131-5. doi:10.1016/0006-291X(84)91209-9

108. Divry P, Florkin M. Sur les proprietes optiques de l'amyloide. C R Seances Soc Biol Fil (Paris) (1927) 97:1808-10.

109. Sherrington R, Rogaev EI, Liang Y, Rogaeva EA, Levesque G, Ikeda M, et al. Cloning of a gene bearing missense mutations in early-onset familial Alzheimer's disease. Nature (1995) 375(6534):754-60. doi:10.1038/ 375754a0

110. Levy-Lahad E, Wasco W, Poorkaj P, Romano DM, Oshima J, Pettingell WH, et al. Candidate gene for the chromosome 1 familial Alzheimer's disease locus. Science (1995) 269(5226):973-7. doi:10.1126/science.7638621

111. Kitazawa M, Medeiros R, Laferla FM. Transgenic mouse models of Alzheimer disease: developing a better model as a tool for therapeutic interventions. Curr Pharm Des (2012) 18(8):1131-47. doi:10.2174/138161212799315786

112. Hamanaka H, Katoh-Fukui Y, Suzuki K, Kobayashi M, Suzuki R, Motegi Y, et al. Altered cholesterol metabolism in human apolipoprotein E4 knock-in mice. Hum Mol Genet (2000) 9(3):353-61. doi:10.1093/hmg/9.3.353

113. Tai LM, Youmans KL, Jungbauer L, Yu C, Ladu MJ. Introducing human APOE into Abeta transgenic mouse models. Int J Alzheimers Dis (2011) 2011:810981. doi:10.4061/2011/810981

114. Hsiao K, Chapman P, Nilsen S, Eckman C, Harigaya Y, Younkin S, et al. Correlative memory deficits, Abeta elevation, and amyloid plaques in transgenic mice. Science (1996) 274(5284):99-102. doi:10.1126/ science.274.5284.99

115. Frautschy SA, Yang F, Irrizarry M, Hyman B, Saido TC, Hsiao K, et al. Microglial response to amyloid plaques in APPsw transgenic mice. Am J Pathol (1998) 152(1):307-17.

116. Duff K, Eckman C, Zehr C, Yu X, Prada CM, Perez-tur J, et al. Increased amyloid-beta42(43) in brains of mice expressing mutant presenilin 1. Nature (1996) 383(6602):710-3. doi:10.1038/383710a0

117. Holcomb L, Gordon MN, McGowan E, Yu X, Benkovic S, Jantzen P, et al. Accelerated Alzheimer-type phenotype in transgenic mice carrying both mutant amyloid precursor protein and presenilin 1 transgenes. Nat Med (1998) 4(1):97-100. doi:10.1038/nm0198-097

118. Gordon MN, Holcomb LA, Jantzen PT, DiCarlo G, Wilcock D, Boyett KW, et al. Time course of the development of Alzheimer-like pathology in the 
doubly transgenic PS1+APP mouse. Exp Neurol (2002) 173(2):183-95. doi:10.1006/exnr.2001.7754

119. Stover KR, Campbell MA, Van Winssen CM, Brown RE. Early detection of cognitive deficits in the $3 \mathrm{xTg}$-AD mouse model of Alzheimer's disease. Behav Brain Res (2015) 289:29-38. doi:10.1016/j.bbr.2015.04.012

120. Oddo S, Caccamo A, Shepherd JD, Murphy MP, Golde TE, Kayed R, et al. Triple-transgenic model of Alzheimer's disease with plaques and tangles: intracellular Abeta and synaptic dysfunction. Neuron (2003) 39(3):409-21. doi:10.1016/S0896-6273(03)00434-3

121. Billings LM, Oddo S, Green KN, McGaugh JL, LaFerla FM. Intraneuronal Abeta causes the onset of early Alzheimer's disease-related cognitive deficits in transgenic mice. Neuron (2005) 45(5):675-88. doi:10.1016/j. neuron.2005.01.040

122. Oakley H, Cole SL, Logan S, Maus E, Shao P, Craft J, et al. Intraneuronal beta-amyloid aggregates, neurodegeneration, and neuron loss in transgenic mice with five familial Alzheimer's disease mutations: potential factors in amyloid plaque formation. J Neurosci (2006) 26(40):10129-40. doi:10.1523/ JNEUROSCI.1202-06.2006

123. Kimura R, Ohno M. Impairments in remote memory stabilization precede hippocampal synaptic and cognitive failures in 5XFAD Alzheimer mouse model. Neurobiol Dis (2009) 33(2):229-35. doi:10.1016/j.nbd.2008.10.006

124. Knouff C, Hinsdale ME, Mezdour H, Altenburg MK, Watanabe M, Quarfordt SH, et al. Apo E structure determines VLDL clearance and atherosclerosis risk in mice. J Clin Invest (1999) 103(11):1579-86. doi:10.1172/ JCI6172

125. Youmans KL, Tai LM, Nwabuisi-Heath E, Jungbauer L, Kanekiyo T, Gan M, et al. APOE4-specific changes in Abeta accumulation in a new transgenic mouse model of Alzheimer disease. J Biol Chem (2012) 287(50):41774-86. doi:10.1074/jbc.M112.407957

126. Rosenthal N, Brown $S$. The mouse ascending: perspectives for human-disease models. Nat Cell Biol (2007) 9(9):993-9. doi:10.1038/ncb437

127. Lv X, Li W, Luo Y, Wang D, Zhu C, Huang ZX, et al. Exploring the differences between mouse mAbeta(1-42) and human hAbeta(1-42) for Alzheimer's disease related properties and neuronal cytotoxicity. Chem Commun (Camb) (2013) 49(52):5865-7. doi:10.1039/c3cc40779a

128. Gonzalez-Dominguez R, Garcia-Barrera T, Vitorica J, Gomez-Ariza JL. Metabolomic screening of regional brain alterations in the APP/PS1 transgenic model of Alzheimer's disease by direct infusion mass spectrometry. J Pharm Biomed Anal (2015) 102:425-35. doi:10.1016/j.jpba.2014.10.009

129. Gonzalez-Dominguez R, Garcia-Barrera T, Vitorica J, Gomez-Ariza JL. Application of metabolomics based on direct mass spectrometry analysis for the elucidation of altered metabolic pathways in serum from the APP/ PS1 transgenic model of Alzheimer's disease. J Pharm Biomed Anal (2015) 107:378-85. doi:10.1016/j.jpba.2015.01.025

130. Pan X, Nasaruddin MB, Elliott CT, McGuinness B, Passmore AP, Kehoe PG, et al. Alzheimer's disease-like pathology has transient effects on the brain and blood metabolome. Neurobiol Aging (2016) 38:151-63. doi:10.1016/j. neurobiolaging.2015.11.014

131. Pan X, Elliott CT, McGuinness B, Passmore P, Kehoe PG, Holscher C, et al. Metabolomic profiling of bile acids in clinical and experimental samples of Alzheimer's disease. Metabolites (2017) 7(2):28-39. doi:10.3390/ metabo7020028

132. Yu J, Kong L, Zhang A, Han Y, Liu Z, Sun H, et al. High-throughput metabolomics for discovering potential metabolite biomarkers and metabolic mechanism from the APPswe/PS1dE9 transgenic model of Alzheimer's disease. J Proteome Res (2017) 4:7467. doi:10.1021/acs.jproteome.7b00206

133. Kimball BA, Wilson DA, Wesson DW. Alterations of the volatile metabolome in mouse models of Alzheimer's disease. Sci Rep (2016) 6:19495. doi:10.1038/ srep19495

134. Daugherty D, Goldberg J, Fischer W, Dargusch R, Maher P, Schubert D. A novel Alzheimer's disease drug candidate targeting inflammation and fatty acid metabolism. Alzheimers Res Ther (2017) 9(1):50. doi:10.1186/ s13195-017-0277-3

135. Xia H, Wu L, Chu M, Feng H, Lu C, Wang Q, et al. Effects of breviscapine on amyloid beta 1-42 induced Alzheimer's disease mice: a HPLC-QTOF-MS based plasma metabonomics study. JChromatogr B Analyt Technol Biomed Life Sci (2017) 1057:92-100. doi:10.1016/j.jchromb.2017.05.003
136. van Gijsel-Bonnello M, Baranger K, Benech P, Rivera S, Khrestchatisky M, de Reggi M, et al. Metabolic changes and inflammation in cultured astrocytes from the $5 \mathrm{xFAD}$ mouse model of Alzheimer's disease: alleviation by pantethine. PLoS One (2017) 12(4):e0175369. doi:10.1371/journal.pone. 0175369

137. Ulland TK, Song WM, Huang SC, Ulrich JD, Sergushichev A, Beatty WL et al. TREM2 maintains microglial metabolic fitness in Alzheimer's disease. Cell (2017) 170(4):649-63.e13. doi:10.1016/j.cell.2017.07.023

138. Martorana A, Koch G. Is dopamine involved in Alzheimer's disease? Front Aging Neurosci (2014) 6:252. doi:10.3389/fnagi.2014.00252

139. Nobili A, Latagliata EC, Viscomi MT, Cavallucci V, Cutuli D, Giacovazzo G, et al. Dopamine neuronal loss contributes to memory and reward dysfunction in a model of Alzheimer's disease. Nat Commun (2017) 8:14727. doi:10.1038/ ncomms 14727

140. Mattson MP. Pathways towards and away from Alzheimer's disease. Nature (2004) 430(7000):631-9. doi:10.1038/nature02621

141. De Strooper B, Karran E. The cellular phase of Alzheimer's disease. Cell (2016) 164(4):603-15. doi:10.1016/j.cell.2015.12.056

142. de la Monte SM, Tong M. Brain metabolic dysfunction at the core of Alzheimer's disease. Biochem Pharmacol (2014) 88(4):548-59. doi:10.1016/j. bcp.2013.12.012

143. Dennis EA, Norris PC. Eicosanoid storm in infection and inflammation. Nat Rev Immunol (2015) 15(8):511-23. doi:10.1038/nri3859

144. Herbst-Robinson KJ, Liu L, James M, Yao Y, Xie SX, Brunden KR. Inflammatory eicosanoids increase amyloid precursor protein expression via activation of multiple neuronal receptors. Sci Rep (2015) 5:18286. doi:10.1038/srep18286

145. Hensley K. Neuroinflammation in Alzheimer's disease: mechanisms, pathologic consequences, and potential for therapeutic manipulation. J Alzheimers Dis (2010) 21(1):1-14. doi:10.3233/JAD-2010-1414

146. Thomas C, Pellicciari R, Pruzanski M, Auwerx J, Schoonjans K. Targeting bile-acid signalling for metabolic diseases. Nat Rev Drug Discov (2008) 7(8):678-93. doi:10.1038/nrd2619

147. Festa C, De Marino S, Carino A, Sepe V, Marchiano S, Cipriani S, et al. Targeting bile acid receptors: discovery of a potent and selective farnesoid $\mathrm{X}$ receptor agonist as a new lead in the pharmacological approach to liver diseases. Front Pharmacol (2017) 8:162. doi:10.3389/fphar.2017.00162

148. Schroeder BO, Backhed F. Signals from the gut microbiota to distant organs in physiology and disease. Nat Med (2016) 22(10):1079-89. doi:10.1038/ $\mathrm{nm} .4185$

149. Sola S, Castro RE, Laires PA, Steer CJ, Rodrigues CM. Tauroursodeoxycholic acid prevents amyloid-beta peptide-induced neuronal death via a phosphatidylinositol 3-kinase-dependent signaling pathway. Mol Med (2003) 9(9-12):226-34. doi:10.2119/2003-00042.Rodrigues

150. Lo AC, Callaerts-Vegh Z, Nunes AF, Rodrigues CM, D'Hooge R. Tauroursodeoxycholic acid (TUDCA) supplementation prevents cognitive impairment and amyloid deposition in APP/PS1 mice. Neurobiol Dis (2013) 50:21-9. doi:10.1016/j.nbd.2012.09.003

151. Ackerman HD, Gerhard GS. Bile acids in neurodegenerative disorders. Front Aging Neurosci (2016) 8:263. doi:10.3389/fnagi.2016.00263

152. Nunes AF, Amaral JD, Lo AC, Fonseca MB, Viana RJ, Callaerts-Vegh Z, et al. TUDCA, a bile acid, attenuates amyloid precursor protein processing and amyloid-beta deposition in APP/PS1 mice. Mol Neurobiol (2012) 45(3):440-54. doi:10.1007/s12035-012-8256-y

153. Keene CD, Rodrigues CM, Eich T, Chhabra MS, Steer CJ, Low WC. Tauroursodeoxycholic acid, a bile acid, is neuroprotective in a transgenic animal model of Huntington's disease. Proc Natl Acad Sci U S A (2002) 99(16):10671-6. doi:10.1073/pnas.162362299

154. Camilleri M, Gores GJ. Therapeutic targeting of bile acids. Am J Physiol Gastrointest Liver Physiol (2015) 309(4):G209-15. doi:10.1152/ ajpgi.00121.2015

155. Amaral JD, Viana RJ, Ramalho RM, Steer CJ, Rodrigues CM. Bile acids: regulation of apoptosis by ursodeoxycholic acid. J Lipid Res (2009) 50(9):1721-34. doi:10.1194/jlr.R900011-JLR200

156. Ridlon JM, Harris SC, Bhowmik S, Kang DJ, Hylemon PB. Consequences of bile salt biotransformations by intestinal bacteria. Gut Microbes (2016) 7(1):22-39. doi:10.1080/19490976.2015.1127483 
157. Kim HY, Kim HV, Yoon JH, Kang BR, Cho SM, Lee S, et al. Taurine in drinking water recovers learning and memory in the adult APP/PS1 mouse model of Alzheimer's disease. Sci Rep (2014) 4:7467. doi:10.1038/srep07467

158. Kema IP, Schellings AM, Meiborg G, Hoppenbrouwers CJ, Muskiet FA. Influence of a serotonin- and dopamine-rich diet on platelet serotonin content and urinary excretion of biogenic amines and their metabolites. Clin Chem (1992) 38(9):1730-6.

159. Meltzer CC, Smith G, DeKosky ST, Pollock BG, Mathis CA, Moore RY, et al. Serotonin in aging, late-life depression, and Alzheimer's disease: the emerging role of functional imaging. Neuropsychopharmacology (1998) 18(6):407-30. doi:10.1016/S0893-133X(97)00194-2

160. Geldenhuys WJ, Van der Schyf CJ. Role of serotonin in Alzheimer's disease: a new therapeutic target? CNS Drugs (2011) 25(9):765-81. doi:10.2165/11590190-000000000-00000

161. Pype S, Moechars D, Dillen L, Mercken M. Characterization of amyloid beta peptides from brain extracts of transgenic mice overexpressing the London mutant of human amyloid precursor protein. J Neurochem (2003) 84(3):602-9. doi:10.1046/j.1471-4159.2003.01556.x

162. Chishti MA, Yang DS, Janus C, Phinney AL, Horne P, Pearson J, et al. Earlyonset amyloid deposition and cognitive deficits in transgenic mice expressing a double mutant form of amyloid precursor protein 695. J Biol Chem (2001) 276(24):21562-70. doi:10.1074/jbc.M100710200

163. Inamdar AA, Hossain MM, Bernstein AI, Miller GW, Richardson JR, Bennett JW. Fungal-derived semiochemical 1-octen-3-ol disrupts dopamine packaging and causes neurodegeneration. Proc Natl Acad Sci U S A (2013) 110(48):19561-6. doi:10.1073/pnas.1318830110

164. Hung SY, Fu WM. Drug candidates in clinical trials for Alzheimer's disease. J Biomed Sci (2017) 24(1):47. doi:10.1186/s12929-017-0355-7

165. Prior M, Goldberg J, Chiruta C, Farrokhi C, Kopynets M, Roberts AJ, et al. Selecting for neurogenic potential as an alternative for Alzheimer's disease drug discovery. Alzheimers Dement (2016) 12(6):678-86. doi:10.1016/j. jalz.2016.03.016

166. Chen Q, Prior M, Dargusch R, Roberts A, Riek R, Eichmann C, et al. A novel neurotrophic drug for cognitive enhancement and Alzheimer's disease. PLoS One (2011) 6(12):e27865. doi:10.1371/journal.pone.0027865

167. Lim GP, Chu T, Yang F, Beech W, Frautschy SA, Cole GM. The curry spice curcumin reduces oxidative damage and amyloid pathology in an Alzheimer transgenic mouse. J Neurosci (2001) 21(21):8370-7.

168. Ewers M, Sperling RA, Klunk WE, Weiner MW, Hampel H. Neuroimaging markers for the prediction and early diagnosis of Alzheimer's disease dementia. Trends Neurosci (2011) 34(8):430-42. doi:10.1016/j.tins.2011. 05.005

169. Yao J, Rettberg JR, Klosinski LP, Cadenas E, Brinton RD. Shift in brain metabolism in late onset Alzheimer's disease: implications for biomarkers and therapeutic interventions. Mol Aspects Med (2011) 32(4-6):247-57. doi:10.1016/j.mam.2011.10.005

170. Kano M, Ohno-Shosaku T, Hashimotodani Y, Uchigashima M, Watanabe M. Endocannabinoid-mediated control of synaptic transmission. Physiol Rev (2009) 89(1):309-80. doi:10.1152/physrev.00019.2008

171. Chen R, Zhang J, Wu Y, Wang D, Feng G, Tang YP, et al. Monoacylglycerol lipase is a therapeutic target for Alzheimer's disease. Cell Rep (2012) 2(5):1329-39. doi:10.1016/j.celrep.2012.09.030

172. Maaloe T, Schmidt EB, Svensson M, Aardestrup IV, Christensen JH. The effect of n-3 polyunsaturated fatty acids on leukotriene $B(4)$ and leukotriene $\mathrm{B}(5)$ production from stimulated neutrophil granulocytes in patients with chronic kidney disease. Prostaglandins Leukot Essent Fatty Acids (2011) 85(1):37-41. doi:10.1016/j.plefa.2011.04.004

173. Lutz CS, Cornett AL. Regulation of genes in the arachidonic acid metabolic pathway by RNA processing and RNA-mediated mechanisms. Wiley Interdiscip Rev RNA (2013) 4(5):593-605. doi:10.1002/wrna.1183

174. Chouinard F, Lefebvre JS, Navarro P, Bouchard L, Ferland C, LalancetteHebert M, et al. The endocannabinoid 2-arachidonoyl-glycerol activates human neutrophils: critical role of its hydrolysis and de novo leukotriene B4 biosynthesis. J Immunol (2011) 186(5):3188-96. doi:10.4049/ jimmunol.1002853

175. Gao J, Chen G, He H, Liu C, Xiong X, Li J, et al. Therapeutic effects of breviscapine in cardiovascular diseases: a review. Front Pharmacol (2017) 8:289. doi:10.3389/fphar.2017.00289
176. Zhu JT, Choi RC, Li J, Xie HQ, Bi CW, Cheung AW, et al. Estrogenic and neuroprotective properties of scutellarin from Erigeron breviscapus: a drug against postmenopausal symptoms and Alzheimer's disease. Planta Med (2009) 75(14):1489-93. doi:10.1055/s-0029-1185776

177. Wyss-Coray T, Rogers J. Inflammation in Alzheimer disease - a brief review of the basic science and clinical literature. Cold Spring Harb Perspect Med (2012) 2(1):a006346. doi:10.1101/cshperspect.a006346

178. Penet MF, Abou-Hamdan M, Coltel N, Cornille E, Grau GE, de Reggi M, et al. Protection against cerebral malaria by the low-molecular-weight thiol pantethine. Proc Natl Acad Sci U S A (2008) 105(4):1321-6. doi:10.1073/ pnas.0706867105

179. Kavian N, Marut W, Servettaz A, Nicco C, Chereau C, Lemarechal H, et al. Pantethine prevents murine systemic sclerosis through the inhibition of microparticle shedding. Arthritis Rheumatol (2015) 67(7):1881-90. doi:10.1002/art.39121

180. Rana A, Seinen E, Siudeja K, Muntendam R, Srinivasan B, van der Want JJ, et al. Pantethine rescues a Drosophila model for pantothenate kinase-associated neurodegeneration. Proc Natl Acad Sci U S A (2010) 107(15):6988-93. doi:10.1073/pnas.0912105107

181. Cornille E, Abou-Hamdan M, Khrestchatisky M, Nieoullon A, de Reggi M, Gharib B. Enhancement of L-3-hydroxybutyryl-CoA dehydrogenase activity and circulating ketone body levels by pantethine. Relevance to dopaminergic injury. BMC Neurosci (2010) 11:51. doi:10.1186/1471-220211-51

182. Brunetti D, Dusi S, Giordano C, Lamperti C, Morbin M, Fugnanesi V, et al. Pantethine treatment is effective in recovering the disease phenotype induced by ketogenic diet in a pantothenate kinase-associated neurodegeneration mouse model. Brain (2014) 137(Pt 1):57-68. doi:10.1093/brain/ awt325

183. Paloneva J, Manninen T, Christman G, Hovanes K, Mandelin J, Adolfsson R, et al. Mutations in two genes encoding different subunits of a receptor signaling complex result in an identical disease phenotype. Am J Hum Genet (2002) 71(3):656-62. doi:10.1086/342259

184. Guerreiro R, Hardy J. Genetics of Alzheimer's disease. Neurotherapeutics (2014) 11(4):732-7. doi:10.1007/s13311-014-0295-9

185. Wang Y, Cella M, Mallinson K, Ulrich JD, Young KL, Robinette ML, et al. TREM2 lipid sensing sustains the microglial response in an Alzheimer's disease model. Cell (2015) 160(6):1061-71. doi:10.1016/j.cell.2015.01.049

186. Shimobayashi M, Hall MN. Making new contacts: the mTOR network in metabolism and signalling crosstalk. Nat Rev Mol Cell Biol (2014) 15(3):15562. doi:10.1038/nrm3757

187. Walker JB. Creatine: biosynthesis, regulation, and function. Adv Enzymol Relat Areas Mol Biol (1979) 50:177-242.

188. Huang YA, Zhou B, Wernig M, Sudhof TC. ApoE2, ApoE3, and ApoE4 differentially stimulate APP transcription and Abeta secretion. Cell (2017) 168(3):427-41.e21. doi:10.1016/j.cell.2016.12.044

189. Hattori C, Asai M, Onishi H, Sasagawa N, Hashimoto Y, Saido TC, et al. BACE1 interacts with lipid raft proteins. J Neurosci Res (2006) 84(4):912-7. doi:10.1002/jnr.20981

190. Grimm MO, Mett J, Grimm HS, Hartmann T. APP function and lipids: a bidirectional link. Front Mol Neurosci (2017) 10:63. doi:10.3389/ fnmol.2017.00063

191. Eckert GP, Muller WE. Presenilin 1 modifies lipid raft composition of neuronal membranes. Biochem Biophys Res Commun (2009) 382(4):673-7. doi:10.1016/j.bbrc.2009.03.070

192. Hagen N, Hans M, Hartmann D, Swandulla D, van Echten-Deckert G. Sphingosine-1-phosphate links glycosphingolipid metabolism to neurodegeneration via a calpain-mediated mechanism. Cell Death Differ (2011) 18(8):1356-65. doi:10.1038/cdd.2011.7

193. Elbaum-Garfinkle S, Ramlall T, Rhoades E. The role of the lipid bilayer in tau aggregation. Biophys J (2010) 98(11):2722-30. doi:10.1016/j.bpj.2010. 03.013

194. Xi B, Gu H, Baniasadi H, Raftery D. Statistical analysis and modeling of mass spectrometry-based metabolomics data. Methods Mol Biol (2014) 1198:333-53. doi:10.1007/978-1-4939-1258-2_22

195. Van Cauwenberghe C, Van Broeckhoven C, Sleegers K. The genetic landscape of Alzheimer disease: clinical implications and perspectives. Genet Med (2016) 18(5):421-30. doi:10.1038/gim.2015.117 
196. Willette A. Does metabolic syndrome impact cognition and emotion in Alzheimer's disease? Eur J Neurol (2016) 23(2):237-8. doi:10.1111/ene.12879

197. Wang XF, Lin X, Li DY, Zhou R, Greenbaum J, Chen YC, et al. Linking Alzheimer's disease and type 2 diabetes: novel shared susceptibility genes detected by cFDR approach. J Neurol Sci (2017) 380:262-72. doi:10.1016/j. jns.2017.07.044

198. Rios JA, Cisternas P, Arrese M, Barja S, Inestrosa NC. Is Alzheimer's disease related to metabolic syndrome? A Wnt signaling conundrum. Prog Neurobiol (2014) 121:125-46. doi:10.1016/j.pneurobio.2014.07.004

199. Pistollato F, Sumalla Cano S, Elio I, Masias Vergara M, Giampieri F, Battino M. Role of gut microbiota and nutrients in amyloid formation and pathogenesis of Alzheimer disease. Nutr Rev (2016) 74(10):624-34. doi:10.1093/nutrit/nuw023
200. Demetrius LA, Driver J. Alzheimer's as a metabolic disease. Biogerontology (2013) 14(6):641-9. doi:10.1007/s10522-013-9479-7

Conflict of Interest Statement: The authors declare that the research was conducted in the absence of any commercial or financial relationships that could be construed as a potential conflict of interest.

Copyright (c) 2018 Wilkins and Trushina. This is an open-access article distributed under the terms of the Creative Commons Attribution License (CC BY). The use, distribution or reproduction in other forums is permitted, provided the original author(s) or licensor are credited and that the original publication in this journal is cited, in accordance with accepted academic practice. No use, distribution or reproduction is permitted which does not comply with these terms. 